\title{
Development of a computer-tailored physical activity intervention for prostate and colorectal cancer patients and survivors: OncoActive
}

\author{
R. H. J. Golsteijn ${ }^{1 *}$, C. Bolman ${ }^{1}$, E. Volders ${ }^{1}$, D. A. Peels ${ }^{1}$, H. de Vries ${ }^{2}$ and L. Lechner ${ }^{1}$
}

\begin{abstract}
Background: Cancer and cancer treatment coincide with substantial negative physical, psychological and psychosocial problems. Physical activity (PA) can positively affect the negative effects of cancer and cancer treatment and thereby increase quality of life in CPS. Nevertheless, only a minority of CPS meet PA guidelines. We developed the OncoActive (OncoActief in Dutch) intervention: a computer-tailored PA program to stimulate PA in prostate and colorectal CPS, because to our knowledge there are only a few PA interventions for these specific cancer types in the Netherlands
\end{abstract}

Methods: The OncoActive intervention was developed through systematic adaptation of a proven effective, evidence-based, computer-tailored PA intervention for adults over fifty, called Active Plus. The Intervention Mapping (IM) protocol was used to guide the systematic adaptation. A literature study and interviews with prostate and colorectal CPS and health care professionals revealed that both general and cancer-specific PA determinants are important and should be addressed. Change objectives, theoretical methods and applications and the actual program content were adapted to address the specific needs, beliefs and cancer-related issues of prostate and colorectal CPS. Intervention participants received tailored PA advice three times, on internet and with printed materials, and a pedometer to set goals to improve PA. Pre- and pilot tests showed that the intervention was highly appreciated (target group) and regarded safe and feasible (healthcare professionals). The effectiveness of the intervention is being evaluated in a randomized controlled trial (RCT) $(n=428)$, consisting of an intervention group and a usual care waiting-list control group, with follow-up measurements at three, six and twelve months. Participants are recruited from seventeen hospitals and with posters, flyers and calls in several media.

Discussion: Using the Intervention Mapping protocol resulted in a systematically adapted, theory and evidence-based intervention providing tailored PA advice to prostate and colorectal CPS. If the intervention turns out to be effective in increasing PA, as evaluated in a RCT, possibilities for nationwide implementation and extension to other cancer types will be explored.

Trial registration: The study is registered in the Dutch Trial Register (NTR4296) on November 23rd 2013 and can be accessed at http://www.trialregister.nl/trialreg/admin/rctview.asp?TC=4296.

Keywords: Prostate cancer, Colorectal cancer, Physical activity, eHealth, Computer tailoring, Intervention mapping, Cancer survivorship

\footnotetext{
*Correspondence: rianne.golsteijn@ou.nl

'Department of Psychology and Educational Sciences, Open University of the

Netherlands, Heerlen, POBox 2960, 6401 DL HeerlenThe Netherlands

Full list of author information is available at the end of the article
} 


\section{Background}

The number of newly diagnosed cancer patients and survivors (CPS) will increase significantly given the aging population and improved survival resulting from advances in early detection and cancer treatment $[1,2]$. The growing population of CPS will pose increasing demands on healthcare, as cancer and cancer treatment coincide with substantial negative physical, psychological and psychosocial problems [3-11]. These problems can persist for years or even develop years after treatment. Interventions to reduce these negative effects of cancer and cancer treatment are therefore warranted.

Physical activity (PA) can positively affect the negative effects of cancer and cancer treatment and thereby increase quality of life in CPS [7, 12-21]. PA improves cardiorespiratory fitness and health-related quality of life (HRQoL), and reduces treatment-related side effects, fatigue, pain, distress, anxiety and depression both during and after active treatment [7, 13, 14, 19, 22, 23]. Some studies have even indicated that PA decreases cancer-specific and total mortality risk [24-26]. Besides these positive effects during and after active cancer treatment and on cancer recurrence and survival, being physically active is also important for CPS as they have a higher risk of developing second primary cancers and of developing comorbidities such as cardiovascular disease, diabetes and osteoporosis on which PA has a preventive effect [27].

Despite these benefits, and although PA is regarded as safe and feasible both during and after cancer treatment $[12,27,28]$, only $30-47 \%$ of CPS meet PA guidelines $[29,30]$. Moreover, PA behavior declines during treatment, and does not reach pre-treatment levels after completing treatment $[21,31]$. Thus, interventions to stimulate PA are needed for this population

Diagnosis of cancer can be a 'teachable moment' for behavior change and a majority of CPS are interested in information about PA or participating in an exercise program [21, 32-37]. The majority prefers an unsupervised, home-based PA program, with walking as the preferred exercise mode [21, 34, 36, 38]. However, currently most PA programs in the Netherlands are hospital/ healthcare-based, supervised exercise programs, aimed at sports. Although valuable, these programs are also demanding for both patients and health care professionals. An easily accessible, home-based PA program, aimed at stimulating PA in daily life and leisure time, offered at low costs and requiring minimal staff may offer a valuable alternative. Accordingly, we developed the OncoActive (OncoActief in Dutch) intervention: a computertailored PA program provided online and with printed materials. This paper describes the development process of the intervention, using the Intervention Mapping (IM) protocol and the design of a randomized controlled trial (RCT) to evaluate the effectiveness of the program. The intervention was targeted at prostate and colorectal CPS, because to our knowledge there are only a few PA interventions for these specific cancer types in the Netherlands [39-42]. More detailed rationale for the specific target population can be found in the methods section (needs assessment).

\section{Methods}

The OncoActive intervention was developed through systematic adaptation of a proven effective, evidencebased, computer-tailored PA intervention for adults over fifty, called Active Plus [43, 44]. The Active Plus intervention has been delivered in either a print-based or a web-based version $[45,46]$. Since the median age for a prostate or colorectal cancer diagnosis are 66 and 68 years respectively, and more than 96\% of CPS are aged fifty and over [47], this intervention was assumed to be an ideal starting point. Computer-tailoring provides the opportunity to tailor the content to the specific needs of individual CPS. The IM protocol was used to adapt the intervention in a systematic way [48].

IM provides a systematic approach for the development of theory and evidence-based health promotion programs comprising six steps (Table 1). Although the IM protocol is primarily used to develop new interventions, the protocol is also useful for adapting evidencebased interventions for new target populations as is the case in our study. The protocol helps in finding a balance between containing the core elements of the original intervention while making it relevant for the new target population [48]. The application of these six steps for the development of the OncoActive intervention is briefly described below.

\section{Step 1: Needs assessment}

The OncoActive intervention is aimed at prostate and colorectal CPS. Prostate and colorectal CPS represent a

Table 1 Intervention mapping steps [48]

\begin{tabular}{ll}
\hline Step 1. Needs Assessment & $\begin{array}{l}\text { Assessing the health problem, its impact } \\
\text { on quality of life and its related behavior }\end{array}$ \\
$\begin{array}{ll}\text { Step 2. Program outcomes } \\
\text { and objectives }\end{array}$ & $\begin{array}{l}\text { Adapting performance objectives, } \\
\text { determinants and change objectives } \\
\text { for the new target population }\end{array}$ \\
Step 3. Program design & $\begin{array}{l}\text { Adapting theoretical methods and practical } \\
\text { applications based on new change objectives } \\
\text { or inadequate methods from the original } \\
\text { intervention }\end{array}$ \\
Step 4. Program & $\begin{array}{l}\text { Adapting scope, sequence, materials and } \\
\text { delivery channels and pretesting materials }\end{array}$ \\
Step 5. Program & $\begin{array}{l}\text { Developing an implementation plan for the } \\
\text { implementation plan }\end{array}$ \\
Step 6. Evaluation & $\begin{array}{l}\text { Planning and implementing an effectiveness } \\
\text { and process evaluation for the new program }\end{array}$ \\
\end{tabular}


large proportion of the total CPS population in the Netherlands. Prostate cancer is the most common cancer site among Dutch men with 10,497 new cases in 2015, representing 19\% of all newly diagnosed male cancer patients. Colorectal cancer is the second most common cancer site in both men and women in the Netherlands with 15,549 new cases in 2015, representing $15 \%$ of all newly diagnosed male and female cancer patients. Both cancer types have relatively high survival rates: a 5-year survival rate of $88-99 \%$ for prostate cancer and $62-65 \%$ for colorectal cancer [47, 49]. By selecting only two cancer types, we could better fine-tune the intervention to the specific needs and capabilities of prostate and colorectal CPS.

Cancer and cancer-treatment related side effects have a profound influence on quality of life. Although treatment improves survival rates, the inherent side effects have a negative influence on both physical and social functioning and thereby on quality of life [7, 17]. Prostate and colorectal CPS both experience some similar and some unique treatment related side effects. Decreased muscular strength, decreased physical fitness, functional limitations, bowel dysfunction, sexual dysfunction, altered body constitution, pain, fatigue, sleep disorders, emotional distress, depression, anxiety, fear of recurrence, challenges with body image and cognitive limitations are experienced in both cancer types. Urinary incontinence and hormonal treatment related side effects are more common in prostate cancer, while stoma related limitations, peripheral neuropathy and nausea are more common in colorectal cancer $[3,4,6,10,11$, 17, 50-57]. In particular, colorectal CPS have a higher risk of developing comorbidities such as type II diabetes and cardiovascular disease, second colorectal cancers and other primary cancers $[7,28,58]$.

PA has consistently been shown to improve prostate and colorectal cancer treatment related side effects and thereby quality of life both during and after treatment $[12-15,17,19,20,28,51,54,56,57,59-61]$. PA is also a preventive factor for the associated comorbidities and secondary/new cancers. As a result, PA guidelines for CPS have been established in several countries. International guidelines in general state that CPS should aim to be physically active (moderate to vigorous) for at least 150 min per week [62]. In the Netherlands CPS are advised to adhere (if possible) to the general Dutch PA guidelines, which require them to be physically active with moderate to vigorous intensity for at least $30 \mathrm{~min}$ a day on at least five days per week [63].

Only a minority of CPS adhere to PA guidelines. Adherence to PA guidelines for prostate CPS has been reported to vary between 29 and 47\% [29, 30, 59, 64, 65] and is even lower in colorectal CPS: 20-40\% [29-31, 51, $64,66,67]$. PA levels are known to decline during treatment and do not reach pre-treatment levels after completing treatment $[21,68]$. Thus, the majority do not take full advantage of the positive effects of PA during and after treatment, highlighting the need for an intervention to increase PA in the target group.

The negative effects of cancer and cancer treatment, the positive influence of PA on them and the low and decreasing adherence to PA guidelines already highlight the need for PA programs. Additionally, studies regarding supportive care needs have shown that CPS have a substantial perceived need for healthy lifestyle information and programs including PA [69-71]. According to the literature a majority of CPS are interested in information about PA or participating in a PA program [21, $33-35,37,38,62]$. As a result, the following program goals were formulated: Insufficiently active prostate and colorectal CPS become motivated to be physically active, initiate PA and maintain the newly attained PA level. Physically active prostate and colorectal CPS maintain or slightly increase their PA level.

In order to promote the desired behavior (i.e. being physically active) within the target population it is important to gain more insight into their specific motivating and hindering factors regarding the behavior and preferences in a PA program. Therefore, we systematically searched the literature regarding these topics. To confirm and expand this information we conducted interviews with our target group and healthcare professionals about PA advantages, cancer specific barriers to $\mathrm{PA}$ and information and intervention preferences regarding a computer-tailored intervention among our target group. We conducted twenty-nine semistructured interviews with prostate $(n=18)$ and colorectal $(n=11)$ CPS and fifteen interviews with healthcare professionals (i.e. oncologist/urologist, physiologist, oncology nurse, oncology physiotherapist, oncology trainer) to explore the determinants of PA within the target group and their intervention preferences. Interviews were systematically analyzed with Qualicoder (www.qualicoder.com), according to the framework method [72]. By establishing such a planning group and thus involving the target group and healthcare professionals in the actual intervention development, we were able to take their wishes and preferences for the intervention into account. Findings from the interviews regarding the content of the intervention in relation to the findings from the literature are discussed in steps two and three (which concern determinants and intervention content).

\section{Step 2: Program outcomes and objectives Performance objectives}

The main goal of the OncoActive intervention is to increase and maintain PA behavior of prostate and colorectal cancer CPS, as mentioned in Step1. Further 
specifying this health promoting behavior, in comparison with the original program, is the first task of Step 2 [48]. The original Active Plus intervention was aimed at increasing PA in two ways: by increasing and maintaining leisure time PA and by increasing and maintaining PA in people's daily routines [73]. According to the literature influencing these PA behaviors is also relevant for, and preferred by prostate and colorectal CPS $[21,33,38,74$, 75]. Subsequently specific health promoting behaviors are translated into performance objectives (POs). POs clarify what is expected from someone participating in the intervention and thus performing the desired health promoting behavior [48]. As the specific health promoting behaviors from the original Active Plus intervention are also relevant for prostate and colorectal CPS, the according POs can remain the same for the new target group. POs for the OncoActive intervention are mentioned in Table 2.

\section{Determinants}

Several studies regarding psychosocial determinants of PA in CPS have shown that attitude, subjective norms and perceived behavioral control (constructs of the Theory of Planned Behavior (TBP)) predict intention to engage in PA and PA behavior [68, 76-85]. Pinto and Ciccolo [77] reported that self-efficacy and outcome expectations (constructs of Social Cognitive Theory (SCT)) were important determinants of PA behavior. Higher self-efficacy is associated with more PA [21, 86, 87]. Furthermore, PA interventions based on the Transtheoretical Model (TTM), and thus tailored to the behavioral stage of change, proved to be a predictor of exercise adherence and to be effective in improving fitness, general health and reducing pain and fatigue in CPS $[68,88]$. The I-Change model integrates these theories and models [89].

Based on the original Active Plus intervention [73], important psychological determinants are addressed in

Table 2 Performance objectives for awareness raising, initiation and maintenance of PA among prostate and colorectal CPS

PO.1 Prostate and colorectal CPS monitor their PA level
PO.2 Prostate and colorectal CPS indicate reasons to be physically active
PO.3 Prostate and colorectal CPS identify solutions to take away the
barriers to be physically active
PO.4 Prostate and colorectal CPS decide to become more physically active
PO.5 Prostate and colorectal CPS make specific plans and set goals to
become more physically active
PO.6 Prostate and colorectal CPS increase their PA
PO.7 Prostate and colorectal CPS make specific plans to cope with difficult
situations occurring while being physically active
PO.8 Prostate and colorectal CPS maintain their PA level by enhancing
their routine and preventing relapses

Note: PA includes recreational PA and PA in daily life the OncoActive intervention ranging from pre-motivational determinants (e.g. awareness, knowledge and risk perception), motivational determinants (attitude, social influence beliefs, self-efficacy) and post-motivational determinants (goal setting, action planning) using input from the following social cognitive models: the I-Change Model [89-91] (a model integrating ideas of TPB [92], SCT [93], TTM [94], the Health Belief model [95] and goal setting theories [96, 97]), the Health Action Process Approach [98, 99], theories of self-regulation [100-102] and the Precaution Adoption Process Model [103]. An examination of the literature and interviews with the target group and health care providers regarding the benefits of PA and barriers to PA specifically for prostate and colorectal CPS were conducted to identify differences in the operationalization of the determinants.

\section{Benefits of PA for prostate and colorectal CPS}

In order to increase understanding and motivation of prostate and colorectal CPS towards PA, it is important to inform them about the benefits of PA as attitude is an important predictor of intention for PA [7, 34, 68, 77, 104]. Prove positive effects of PA during and after cancer treatment were identified by a systematic search of the literature and are listed in Table 3 Positive effects include improvements in both physical and mental aspects of health, as well as tertiary prevention of other chronic diseases [7, 19, 56, 60, 105-109].

The outcomes from the interviews with CPS and healthcare professionals (see Table 3 ) largely confirmed the findings from the literature. Although prostate and colorectal CPS did not mention benefits as specific as stated in the literature (for example, better mental health instead of less anxiety or depression), they perceived that PA had beneficial effects on their physical and mental health and enabled them to achieve goals in their daily life. Healthcare professionals additionally mentioned an increased survival and a reduction in the risk for comorbidities [110].

\section{Barriers to PA for prostate and colorectal CPS}

As illustrated in Table 3, according to the literature, both general and cancer-specific barriers can result in CPS not being physically active and should thus get special attention in a PA program $[6,51,62,104,111,112]$. Physical complaints are often dependent on cancer type and the associated treatment. Physical complaints for colorectal CPS may include a stoma, peripheral neuropathy, (urinary) incontinence or diarrhea, nausea and vomiting [51], whereas urinary incontinence is the most important physical complaint in prostate CPS.

The findings from the literature were confirmed in the interviews, with fatigue, pain, incontinence and peripheral neuropathy being the most frequently mentioned barriers for being physically active. Besides cancer-specific barriers, 
Table 3 Benefits of and barriers to PA in prostate and colorectal CPS

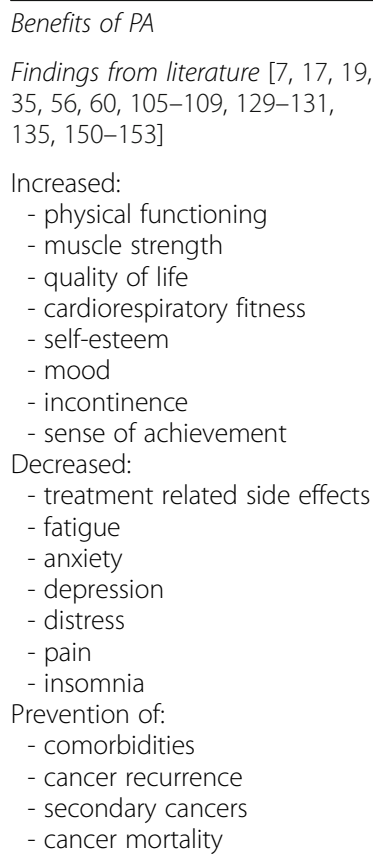

Barriers to $P A$

Findings from literature [7, 34, 35, Findings from interviews [110] $53,82,104,129,130-132,135$

$136,150,151,153-156]$

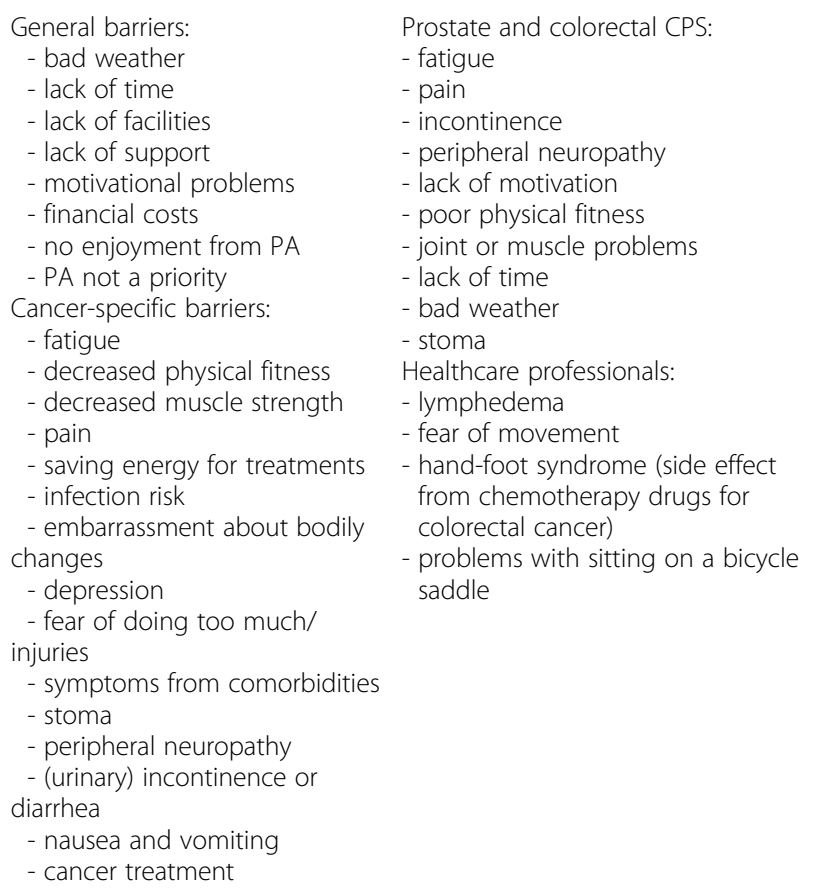

the interviewed CPS also mentioned general barriers including lack of motivation, lack of time and bad weather [110]. Findings are listed in Table 3.

As barriers may prevent CPS from being physically active, it is important that a PA intervention for prostate and colorectal CPS pays special attention to the general barriers, but especially to the cancer-specific barriers. Providing suggestions to overcome the barriers could increase self-efficacy and perceived behavioral control, which are important predictors of intention for PA and actual PA behavior [68].

\section{Change objectives}

Both performance objectives and the determinants that should be addressed are comparable to the original Active Plus intervention. Consequently, major changes in the general structure of the intervention were not regarded as necessary. Yet, findings from both interviews and the literature suggested that the content should also address cancer-specific topics. Determinants like attitude, knowledge and self-efficacy should be directed at the specific needs, beliefs and cancer related issues of CPS.

Therefore, we decided to add and/or adapt some change objectives to address these specific themes. For example, for the PO 'prostate and colorectal CPS identify solutions to take away the barriers to being physically active' combined with the determinant self-efficacy, we added the change objective 'prostate and colorectal CPS feel confident about being able to take away and cope with cancer-specific barriers to being physically active'. Some other examples can be found in Table 4. Findings from the literature and interviews were also used in the production of the intervention content (see Step 4).

\section{Step 3: Program design \\ Theoretical methods, practical applications and intervention preferences for CPS}

Theoretical methods and practical applications are necessary to address the existing, adapted and added change objectives. In order to establish the adoption of an active lifestyle and maintenance of PA, it is important that behavior change techniques are incorporated in the intervention to improve PA behavior in CPS [7, 62]. We searched the literature and interviewed prostate and colorectal CPS regarding relevant theoretical methods and intervention content.

According to Pinto and Ciccolo [77], social-cognitive techniques for self-management, increasing self-efficacy, developing realistic outcome expectations, increasing intention and developing plans in line with motivational readiness are key concepts in a PA program for CPS. Modeling to increase self-efficacy, emphasizing benefits and fun (strengthening attitude) and informing significant others about the importance of PA (subjective norms) are important intervention components according to the Dutch cancer rehabilitation guideline [113].

According to the literature regarding the content that should be addressed with the theoretical methods and practical applications, CPS would like to receive information, 


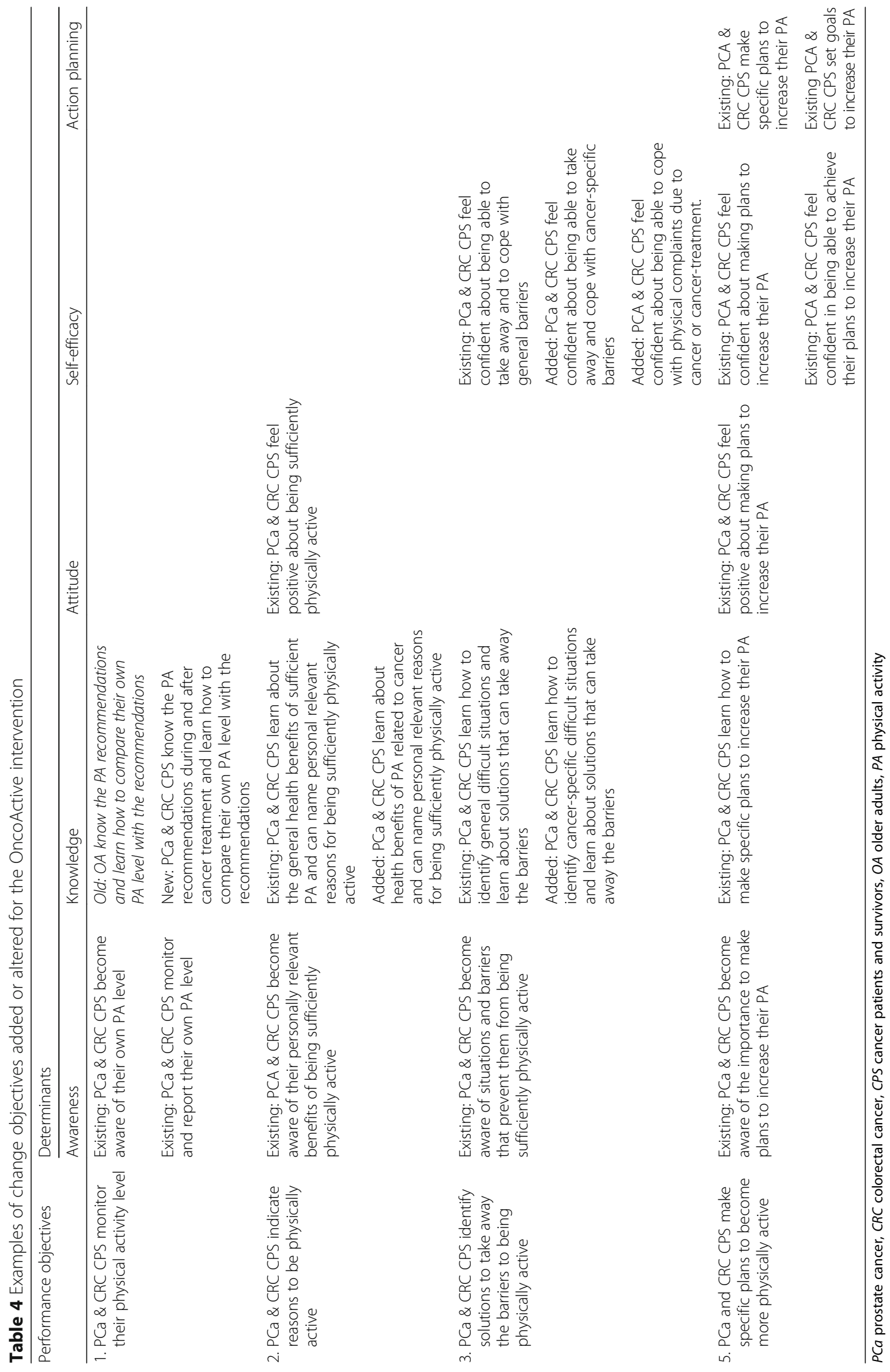


advice and support regarding ways in which they can be physically active, both during and after treatment, the necessity to take special precautions due to illness and treatment, guidance in planning PA and giving notice to and emphasizing PA guidelines to increase awareness and acknowledge maintenance of PA [7, 34, 104]. Findings from our interviews indicated that it was important that a computer-tailored PA program (like the original Active Plus intervention, but adapted to CPS) provided guidance, ways to perform PA and emphasized PA benefits [110]. Healthcare providers suggested more practical things, like the use of graphic materials or videos, providing the possibility to consult with an expert or providing referral to an expert and using social media or apps.

\section{Theoretical methods and applications in the OncoActive intervention}

To optimize participation of CPS in a PA program, it is important that an intervention is tailored to the patients' interests, abilities, opportunities, and preferences [21, 35, 62]. Computer-tailoring provides the opportunity to easily adapt the intervention content to the specific characteristics of a patient to increase personal relevance. It is the core method of the OncoActive intervention (just as in the original Active Plus intervention). Computer tailoring is a method that uses questionnaires to assess characteristics, beliefs, behavior, etc., of the individual participants and automatically produces feedback. The feedback, based on the assessment, is created by using a message library and computer-based if-then algorithms to select the right messages. The feedback is personalized and automatically tailored to the personal characteristics of the participant and can thus also be tailored to cancer-specific needs and beliefs [114, 115]. Computer-tailoring was an effective method in changing PA behavior in the original Active Plus intervention [43, 44]. Several other studies and reviews also confirmed the effectiveness of computer tailoring in achieving behavioral change after providing tailored health promotion advice [114, 116-122].

Other theoretical methods used in the original Active Plus intervention included consciousness raising, selfmonitoring, active learning, reinforcement, social modelling, persuasive communication and argumentation [45, 73]. These methods and the related practical applications can be retained for the OncoActive intervention. Additionally, theoretical methods and practical applications are also applied to the cancer specific content, as a result of the added and altered change objectives. Adding the change objective 'Prostate and colorectal CPS learn about health benefits of PA related to cancer and can name personally relevant reasons for being sufficiently physically active' requires that the practical strategies and content for attitude and knowledge should contain information about cancer-specific (perceived) benefits. A few other examples of the way we adapted the content to the prostate and colorectal CPS group can be found in Table 5. When applying a theoretical method it is important that the underlying theoretical conditions or parameters are respected [48]. For example, SCT [93] states that social modeling is only effective when the presentation of the methods meets certain conditions, such as participant identification with the model. For that reason, the existing role-model videos and pictures (for the paper-based version of the intervention) were replaced by videos and pictures with quotes of real cancer survivors instead of age and sex matched healthy adults.

Besides adjustments to methods and practical strategies regarding the cancer specific content, we also added some new applications based on the findings from the literature and our interviews. As self-efficacy is especially important $[68,123]$ in CPS, and the interviewed CPS and healthcare professionals mentioned the importance of the possibility to consult a professional, the option to consult a physical therapist with questions regarding PA and cancer was added to the intervention.

Although the original Active Plus intervention influenced PA behavior directly and path analyses showed that the intervention also influenced several determinants of PA, we looked for additional methods to enhance monitoring and goal setting to address the intention-behavior gap. Research in general [124-126] and specifically with CPS $[127,128]$ revealed that pedometers can be a valuable application for selfmonitoring of PA behavior and goal setting. Therefore, we added the use of pedometers to the OncoActive intervention. By providing participants with instructions for monitoring, goal setting and adjusting goals, they are encouraged to self-regulate their PA behavior.

The described adaptations in methods and practical strategies were used to adapt existing and to develop new program components as described in the next section.

\section{Step 4: Program production \\ Adaptation of program components}

The adaptation and broadening of change objectives, theoretical methods and practical strategies also requires adaptation of program components. In general, all text messages were checked and if necessary adapted to relate them to the new target group of CPS. Additionally, intervention texts were edited and shortened by a professional editor. Some intervention elements were adapted more extensively and will be discussed below.

As mentioned in steps two and three, operationalization of the determinants for the OncoActive intervention was different from the original Active Plus 


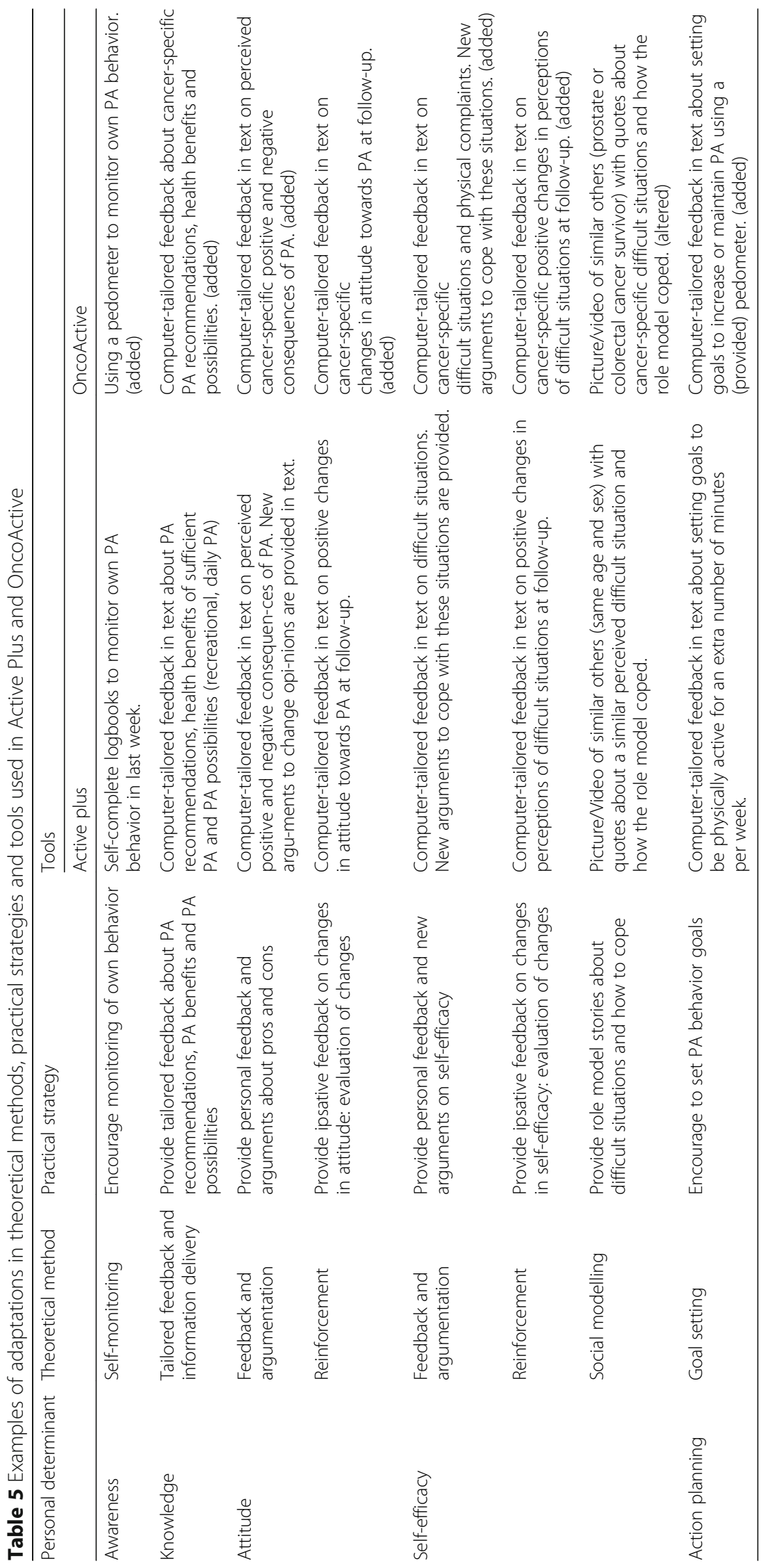


intervention, as we added cancer-specific information regarding benefits of PA, attitude towards PA and difficult situations/barriers regarding PA. The change in determinants also requires adaptation in our screening instrument, in order to be able to tailor the new information to each individual CPS. As mentioned in step two, we searched the literature and used the information from the interviews to identify relevant pros, cons and barriers. This resulted in the addition of pros regarding PA being positively related to: better health, more energy/ less fatigue, cancer recurrence, returning to 'normal' life, treatment related side effects, better bladder control and increased physical fitness $[7,35,56,109,112,129,130]$. Cons were added regarding PA being related to: increased fatigue, increased pain, increased lymphedema, higher risk of infection and hindering recovery from cancer [112, 130-134]. Difficult situations/barriers additionally included in the screening instrument and feedback library were urinary incontinence, feeling bad about bodily appearance, sleeping problems, being under treatment, suffering from treatment related side effects, lack of social support, peripheral neuropathy, afraid of falling, not knowing how much PA is allowed, fecal incontinence/diarrhea and having a stoma [7, 35, $129,130,133-136]$. Some difficult situations, like feeling fatigued or feeling sad which are highly relevant for CPS were already included in the original Active Plus intervention.

Providing information on both the already included (general) and the cancer-specific pros/cons and difficult situation/barriers would result in an overload of information in the OncoActive intervention. Therefore, we decided to provide feedback on a maximum of seven pros, six cons and ten barriers. These were the same number of feedback messages that were given in the original intervention $[45,73]$. As a result of this we had to apply a ranking to the delivered information. As cancerspecific determinants were expected to be of special relevance, we decided to provide feedback on these first. Complimentary feedback regarding the general determinants was provided until the maximum was reached or if there were no additional relevant determinants.

Another adaptation regarding the intervention materials involved the development of texts and information for using the pedometer for monitoring and goal setting. Tailored feedback messages regarding step goals were formulated and linked to the individual PA level of CPS. These messages also included instructions on how participants can continue on their own in setting new step goals once they have reached a goal. In addition to the tailored feedback, a brochure was provided with schemes CPS could use to keep track of their progress regarding their daily step count. The content was also translated into an interactive module on the website, to guide CPS in setting new step goals and monitoring their average daily step count.

As already mentioned in step three, role model videos and pictures of age and sex matched healthy older adults were replaced by pictures with quotes and video content from real cancer survivors. For this new content we conducted video-taped interviews with several cancer survivors. After filming the interviews, the content of the interviews was reviewed and short fragments with suitable quotes were added to the intervention. Colorectal CPS were shown videos/pictures of both (younger and older) males and females, whereas prostate CPS were only shown videos of (younger and older) males. These fragments showed for example which barriers the cancer survivors experienced and how they managed to overcome these barriers.

Based on the results of the interviews with CPS and health care providers, we also developed a module on the website in which CPS within the OncoActive intervention could consult a physical therapist with questions regarding $\mathrm{PA}$, thus allowing them to receive a personal response to problems or difficulties. This module also contained a list with example questions and responses as a frequently asked questions database (FAQ). Participants were encouraged to look at these FAQ. Newly asked questions from participants were added (anonymized) to the 'database'. The aim of this module was to enhance the self-efficacy of CPS to become physically active.

\section{Adaptation of delivery channels}

The original Active Plus intervention was developed in a print-based version (exclusively in print materials, no additional website) [73] and a web-based version (exclusively online, no additional print materials) [45]. However, based on in-depth analyses it was suggested that for optimal effects the best solution would probably be to provide both delivery modes and giving the participant the choice of their preferred delivery mode [46, 137, 138]. Additionally, process evaluation data showed that in the original Active Plus intervention the print materials were used more often and better appreciated [139]. Taking into account these findings we decided to deliver the OncoActive intervention both printed and online alongside each other. In this way people could choose their own preferred delivery channel and webbased materials were supplemented with print-based material for every participant in order to optimize use and appreciation.

Process evaluation data of the original Active Plus intervention additionally indicated that access to the web-based intervention itself and to the web-based intervention materials should be simplified [139]. To simplify web access, we used URL's automatically logging 
people into the right place on the website in e-mails inviting participants to visit the website. Intervention materials were more integrated in the website, as shown in Fig. 1. By integrating forms in this way, participants could start to fill out the form immediately, in contrast to the original Active Plus intervention. Additionally the website was constructed differently to increase the accessibility of the intervention content.

In order to keep participants more involved by visiting the website, we periodically provided them with additional news items, encouraging them to revisit the website. In total three news items were provided. The content and timing is described below.

\section{The intervention}

The adaptation process described above resulted in the adapted OncoActive intervention. As explained in the previous sections the intervention is based on behavior change techniques and aimed at increasing awareness of PA behavior and stimulating PA during leisure time and in daily activities. Intervention participants receive tailored advice at three time points.

\section{First advice}

Participants receive their first advice within two weeks after completing the first questionnaire. The content is based on their answers to this questionnaire. Together with the advice they receive a pedometer (for own use) to monitor their PA behavior and to continually set goals to increase their PA.

\section{Second advice}

The second 'follow-up' advice, which participants receive two months after their first advice, is also based on answers to the first questionnaire. The content of both the first and the second advice is tailored to the behavioral stage of change according to the TTM: topics shown in Table 6, were addressed either in advice one or advice two depending on the stage of change at baseline. The content of the messages was tailored to cancer type and phase (i.e. during or after active treatment).

\section{Third advice}

Three months after the first questionnaire participants receive a new questionnaire and subsequently, within two weeks after completion, a third tailored advice. This final advice addresses changes in PA and PA related determinants since the start of the program. Improvements are rewarded, whereas suggestions for improvement are given in case of stagnation or decline.

\section{News updates}

Additionally, participants receive two or three news updates with extra information by e-mail. The first news update addresses the topic of incontinence and pelvic floor therapy and contains videos in which a pelvic floor therapist provided information. Participants suffering

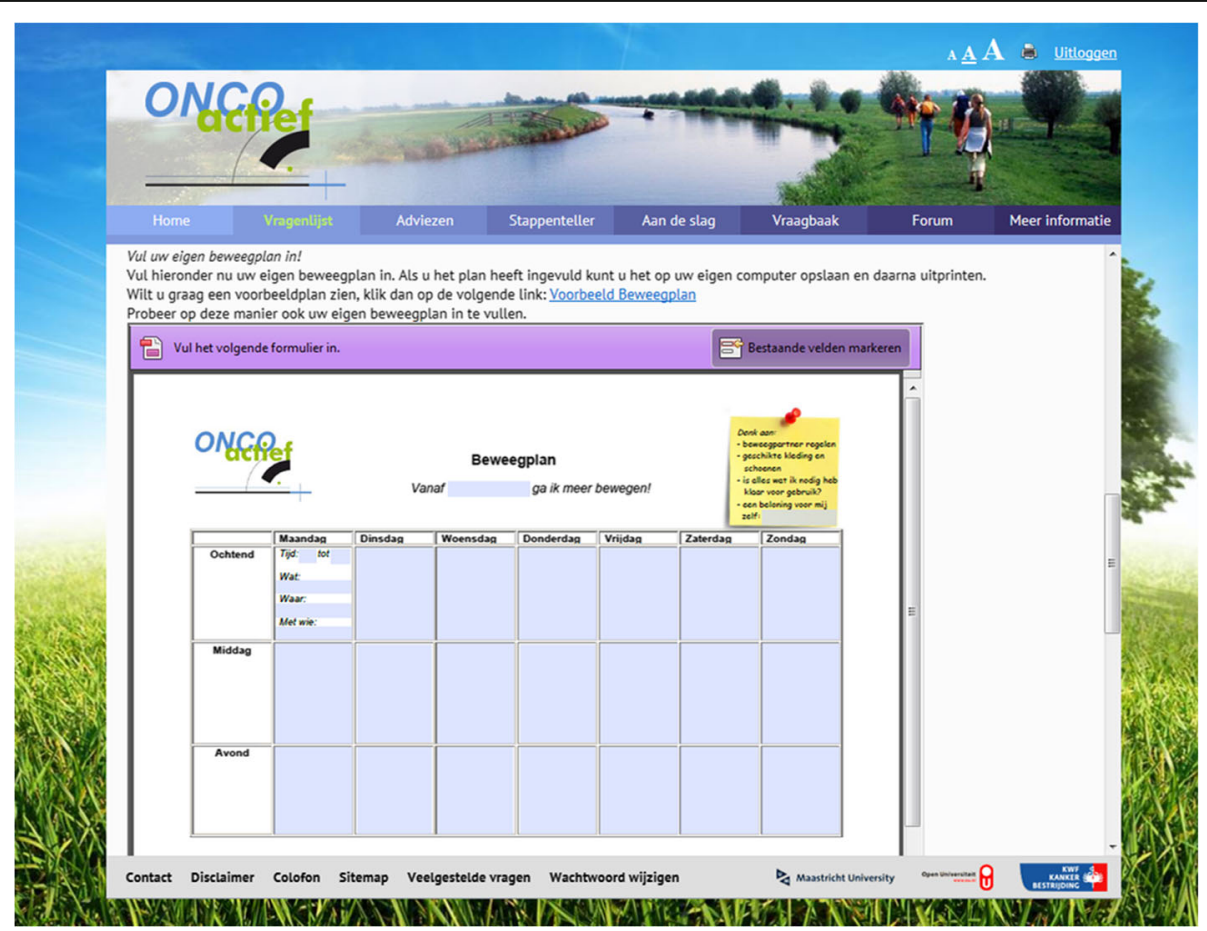

Fig. 1 OncoActive website with integrated intervention materials 
from urinary or fecal incontinence receive an e-mail that there is new content on the website, one month after their first advice.

The second news update contains video content in which a physical therapist explains the importance of PA during and after cancer treatment. All participants receive an e-mail to draw their attention to the new content on the website, six weeks after their first advice.

The third news update reminds participants about using their pedometer and provides them with tips and tricks to collect additional steps during their daily routines. All participants receive a notifying e-mail six weeks after their third (and last) tailored advice. A schematic overview of the intervention is shown in Fig. 2

\section{Delivery channel}

As previously mentioned, CPS can participate in the intervention both online and via paper-based questionnaires and advice. Every participant receives both log-in details for the OncoActive website to fill out the questionnaire and a paper-and-pencil version of the questionnaire. After completion of the questionnaire of their own choice, they receive their tailored advice both on the website and by normal mail. On the website they can also find additional interactive content (e.g. role model videos, home exercise instruction videos), a module for goal setting using the pedometer, the option to consult a physical therapist and additional information. A summary of intervention content and the addressed topics can be found in Table 6 .

\section{Pretest and pilot-test}

As several intervention components were already evaluated within the Active Plus intervention, firstly we pretested newly developed intervention materials among twenty-nine CPS (who also participated in the interviews). We evaluated two possible designs for the websites (see Fig. 3). Design one was significantly more appealing and more appreciated (appeal: 3.7 vs. 3.2 on a $1-5$ scale, $p=.005$; appreciation 7.5 vs. 6.6 on a $1-10$ scale, $p=.003)$. Furthermore, the pedometer, a role model video with a cancer survivor and the discussion group were appreciated as well (7.2, 7.7 and 7.0 respectively on a $1-10$ scale) and valued as useful (3.7, 3.8 and 3.5 respectively on a $1-5$ scale). Text messages for cancer specific barriers were rated 7.0 to 7.5 (on a 1-10) scale, except the text message about being physically active with a stoma, which scored a 5.6. To address this low score, we decided to add a brochure about PA with a stoma, developed by the Dutch stoma association, to the advice. Minor adaptations on the other text messages were made based on the suggestions of CPS.

After finishing intervention development, the complete intervention was evaluated in a small scale pilot study, in which the intervention was delivered to twenty-one CPS in a shortened time frame (i.e. two months instead of four months). CPS were recruited from one hospital and one radiotherapy institute. Findings from this pilot-test showed that the tailored advice was appreciated $(7.5,7.5$ and 7.8 respectively on a $1-10$ scale), as was the intervention overall (8.3 on a $1-10$ scale) [140].The pedometer and cancer specific role

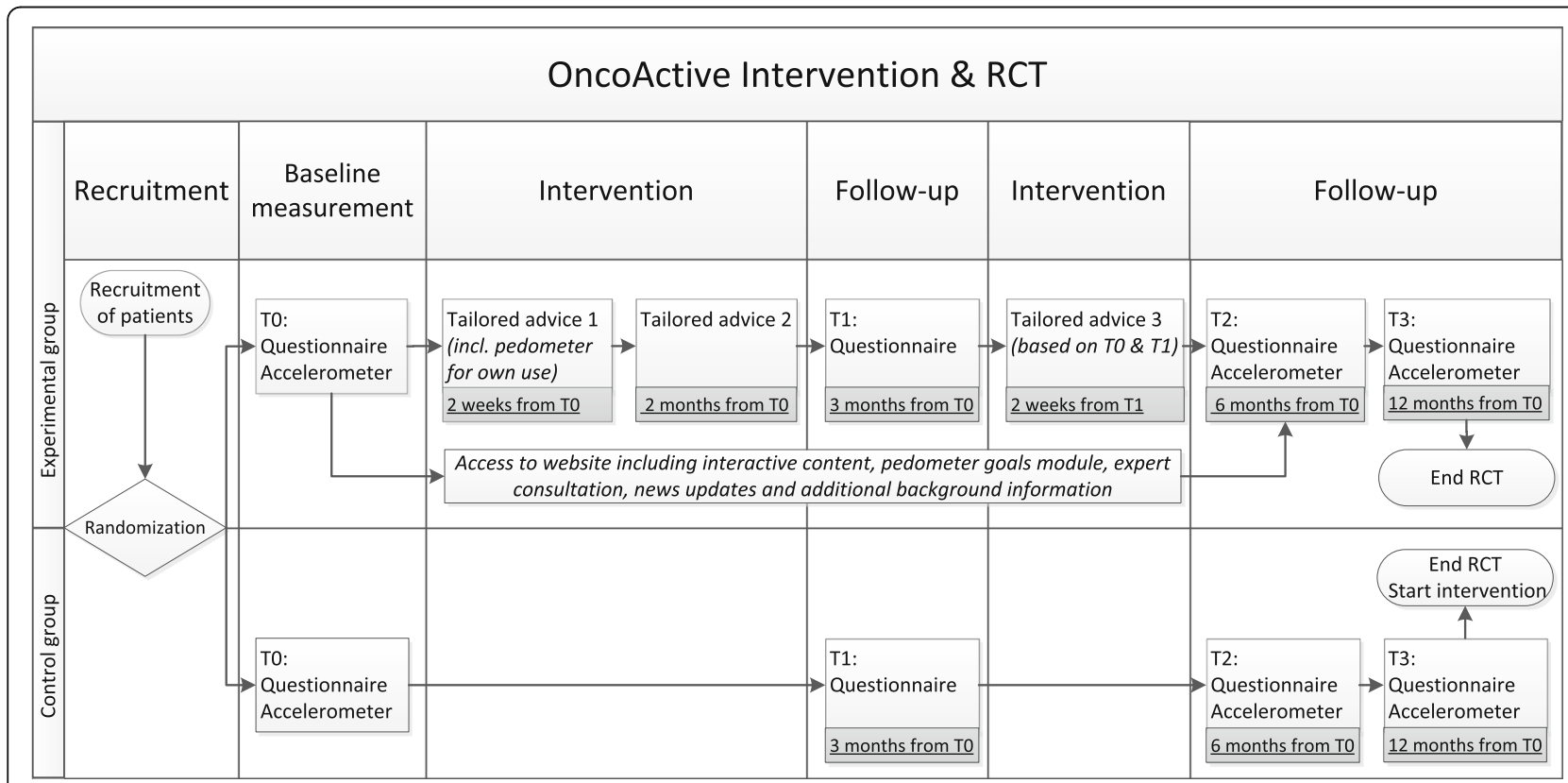

Fig. 2 Schematic overview of the intervention and the associated randomized controlled trial 
Table 6 Content summary of the OncoActive intervention

\begin{tabular}{|c|c|}
\hline Topics computer-tailored advice ${ }^{a}$ & Summary of content ${ }^{a}$ \\
\hline \multicolumn{2}{|l|}{ Advice $1 \& 2$} \\
\hline Awareness & - Graph with own behavior and guideline behavior \\
\hline Knowledge & $\begin{array}{l}\text { - Information regarding guideline } \\
\text { - Information regarding positive effects of PA for prostate and colorectal CPS }\end{array}$ \\
\hline Attitude & - Computer-tailored reflection and explanation on perceived pros and cons of PA \\
\hline Motivation & $\begin{array}{l}\text { - Role model video/picture about most important motivation for being physically active } \\
\text { - Space to write down own (intrinsic) motivation for PA }\end{array}$ \\
\hline Self-efficacy & $\begin{array}{l}\text { - Computer-tailored reflection and explanation on perceived barriers and physical complaints } \\
\text { - Suggestions to overcome barriers and deal with physical complaints } \\
\text { - Role model video/picture demonstrating how to deal with barriers }\end{array}$ \\
\hline PA suggestions & $\begin{array}{l}\text { - Practical suggestions to be physically active according to the CPS' preferences } \\
\text { - Information about walking and cycling routes } \\
\text { - Cancer-specific PA suggestions (e.g. PA groups for CPS) } \\
\text { - Home exercises (video/pictures) }\end{array}$ \\
\hline Goal setting & - Instructions about goal setting and monitoring using a pedometer \\
\hline Action planning & - Scheme to plan PA on a weekly basis \\
\hline Coping planning & - Scheme to construct if-then solutions for barriers or situations in which PA is difficult \\
\hline Social support & $\begin{array}{l}\text { - Encourage CPS to ask for support from their social environment } \\
\text { - Suggestions to find someone to be physically active with }\end{array}$ \\
\hline \multicolumn{2}{|l|}{ Advice 3} \\
\hline Ipsative feedback & $\begin{array}{l}\text { Feedback on: } \\
\text { - Changes in PA behavior, activities and goals } \\
\text { - Changes in health related factors (fatigue, quality of life) } \\
\text { - Changes in PA determinants (intention, attitude, self-efficacy) } \\
\text { - Changes in social support }\end{array}$ \\
\hline Monitoring behavior & $\begin{array}{l}\text { - Scheme to keep track of own PA behavior } \\
\text { - Encouragement to continue pedometer use }\end{array}$ \\
\hline Website components & Explanation \\
\hline Pedometer module & Module for registering pedometer step counts to monitor PA behavior and set new step goals \\
\hline Video content & $\begin{array}{l}\text { Role model videos in which real cancer survivors talk about their own experiences and coping. } \\
\text { Instruction videos with home exercises. }\end{array}$ \\
\hline Expert consultation and FAQ & $\begin{array}{l}\text { Module in which CPS can consult a physical therapist with questions regarding PA. Frequently } \\
\text { asked questions are also shown. }\end{array}$ \\
\hline Discussion group & Online discussion group in which CPS can exchange information, experiences and questions \\
\hline Background information & $\begin{array}{l}\text { Complementary information regarding nutrition, return to work, other website and interesting } \\
\text { mobile applications }\end{array}$ \\
\hline News update message & $\begin{array}{l}\text { News messages regarding pelvic floor therapy, expert opinion about PA and cancer and tips and } \\
\text { tricks to increase PA using a pedometer }\end{array}$ \\
\hline
\end{tabular}

a Sequence and content of topics are adjusted to the stage of change of the CPS

model stories (i.e. new intervention components) were highly appreciated (8.5 and 7.7 on a $1-10$ scale) and regarded as useful (4.2 and 3.9 on a $1-5$ scale), especially the pedometer [140]. The newly developed website's usability was evaluated using the System Usability Scale [141] and scored a 68.86 on this scale. According to this scale a score of 68 can be seen as average. Website components, i.e. the consultation of a physical therapist and additional background information were also appreciated (7.3 and 8.8 on a $1-10$ scale) and regarded as useful (3.7 and 4.6 on a $1-5$ scale). Lastly we also evaluated self-reported PA. Although we did not find a significant pre- to post-test increase in the minutes of moderate to vigorous PA, we found (even in the short time period) a significant increase in the number of days CPS reported being physically active for at least $30 \mathrm{~min}$ (3.8 vs. 5.3, $p=.005)$.

As the intervention and the newly developed components received good scores on the pilot test, we decided not to adapt these components. In the pilot we tried to use a Facebook group as a discussion group. However, as this was not broadly used in the pilot study and because it was difficult to guarantee the privacy of the participants, as well as being difficult to integrate a Facebook 


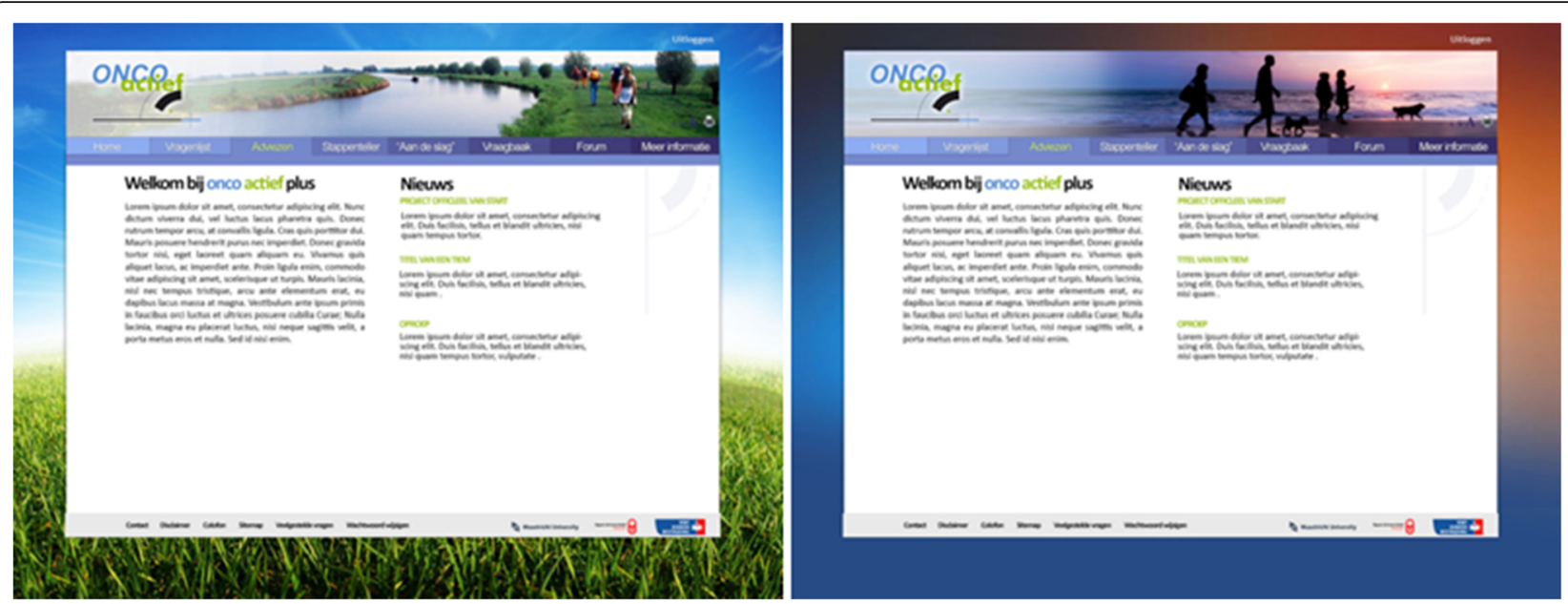

Fig. 3 Potential website designs (design one on left) for the OncoActive intervention

group on the website, we decided to use a normal discussion forum for the final intervention. Additionally we noticed that participants had difficulties with filling out some parts of the questionnaires, such as the treatments they received and the social support and modeling they received from fellow CPS. Therefore, we decided to ask questions about received treatments together with a question about the type of cancer (i.e. prostate or colorectal) in a small questionnaire added to the informed consent form. In this way we had the opportunity to clarify ambiguities, in order to be assured that the participants received advice that matched their personal situation. With regard to the questions about social support and modeling from fellow CPS, we decided to drop this from the interventions, as it turned out that participants often did not know fellow CPS very well.

Finally, we also pretested the safety and feasibility of the content with cancer care professionals $(n=11)$ who also participated in the interviews. The scores in Table 7 show that the intervention content was regarded as highly feasible and safe. Minor adaptations (i.e. framing of a sentence) were made to the intervention texts based on suggestions of the cancer care professionals.

Table 7 Expert rating of the intervention content regarding safety and feasibility

\begin{tabular}{ll}
\hline Topics & $\begin{array}{l}\text { Mean (SD) } \\
\text { (scale 1-5) }\end{array}$ \\
\hline Medical information is accurate & $4.1 \pm 0.8$ \\
PA recommendations are safe and suitable & $4.4 \pm 0.7$ \\
Sufficient safety precautions are taken & $4.3 \pm 0.9$ \\
Suitable for patients currently undergoing treatment & $4.3 \pm 0.6$ \\
Suitable for patients who finished treatment & $4.4 \pm 0.5$ \\
Information fits logic, language \& experience of patients & $4.7 \pm 0.5$ \\
\hline
\end{tabular}

\section{Step 5: Program implementation plan}

For implementation of the OncoActive intervention in a $\mathrm{RCT}$, we created a network of hospitals and radiotherapy institutes in the Netherlands, including the two who participated in the small scale pilot. Contact persons within these institutions were surgeons, oncologists, urologists, research nurses and nurse practitioners. Seventeen hospitals agreed to participate in the active recruitment of CPS. Another five hospitals were not able to provide enough resources to actively recruit CPS, but agreed to distribute posters and flyers. Other reasons for not participating in the recruitment were the presence of (too many) other research projects and that the hospital treated only a few patients who met inclusion criteria.

Additionally daily and weekly regional newspapers, relevant websites and discussion groups were contacted to publish a call for CPS.

\section{Step 6: Evaluation plan}

The final step entailed the development of a plan for the effect and process evaluation of the intervention. For this evaluation we compared an intervention group receiving the OncoActive intervention (who had also access to all usual care) to a usual care only control group in a RCT. The latter group had access to all usual care and received the OncoActive intervention after completion of all research measurements. Participants who provided informed consent to participate were randomly assigned to one of two study arms. The RCT was approved by the Medical Ethics Committee of the Zuyderland hospital (NL47678.096.14) and is registered in the Dutch Trial Register (NTR4296).

\section{Participants}

CPS ( $\geq 18$ years) diagnosed with colorectal or prostate cancer could participate in the trial if they were undergoing 
treatment with a curative intent, or if they successfully completed primary treatment (surgery, chemotherapy or radiation) up to one year ago. Surgery should have taken place at least 6 weeks before the start of the study. CPS with severe medical, psychiatric or cognitive illness which could interfere with participation in a PA program were excluded from participation. Proficient Dutch reading and speaking skills were required for the completion of questionnaires and reading the tailored advice.

\section{Power calculation}

Sample size calculations were based on the outcomes of the previous studies on the effects of the Active Plus intervention. These studies found an effect size of 0.3 and effects were assumed to be comparable in CPS. Calculations showed that approximately 300 participants were needed for the effect study, based on this effect size, a power of .80 with an alpha of.05 and a correction for multilevel analyses (intracluster correlation coefficient $=.005$, design effect $=1.15$ ). Drop-out was expected to be around 30\% during the study, thus 428 participants were needed for enrollment at baseline.

\section{Design and procedure}

Prostate and colorectal CPS were recruited from urology and/or oncology departments of seventeen hospitals in 2015 and 2016. Eligible CPS were identified by hospital staff and verbally informed (either in person or by telephone) about the research. Written information was handed over or sent by mail if the patient agreed to receive this information package. Additionally CPS were recruited with posters and flyers in non-participating hospitals, as well as with calls in local newspapers and on relevant websites and discussion groups. Participants responding to these messages were informed by the researchers and were also sent an information package by mail.

The information package included a letter with information about the study, a time schedule of the study, an informed-consent form and a pre-paid return envelope. Reminders were sent to participants if there was no response on the initial information package. CPS who agreed to participate, were randomized into one of the two research conditions as depicted in Fig. 2. Subsequently they were mailed an accelerometer with instructions to wear it for seven days. After wearing the accelerometer they received a questionnaire both online and on paper, with the choice to fill out one of them. After completing this baseline questionnaire (T0), the intervention group received the OncoActive intervention. Both groups had to fill out follow-up questionnaires at three time points: three (T1), six (T2) and twelve (T3) months after baseline. Participants were also requested to wear the accelerometer the week before they filled out T2 and T3 questionnaires. The control group received the OncoActive intervention after completing the last measurement (T3).

\section{Measurements}

The primary outcome for this study was PA behavior, assessed both objectively with an accelerometer (Activity Monitor GT3X-BT Actigraph, Pensacola, Florida, US) and a validated self-report questionnaire (Short questionnaire to assess health-enhancing physical activity (SQUASH)) [142]. Secondary outcome measures included fatigue [143], anxiety and depression [144, 145], mental adjustment to cancer [146], quality of life [147] and health care consumption. Besides primary and secondary outcomes, CPS were also asked questions about demographics, cancer related characteristics (type of cancer, type of treatment currently undergoing/finished/planned for the near future), PA related determinants (awareness of personal PA level, attitude, self-efficacy, intention toward PA, habit strength). For the purpose of a process evaluation, participants of the intervention group were asked additional questions about use, appreciation, usefulness, readability, attractiveness, personal relevance and understanding of OncoActive. Besides the questionnaires, the use of the website and all accompanying elements were logged during the intervention period.

\section{Discussion}

The purpose of this paper was to describe the systematic development process of the OncoActive intervention, a computer-tailored PA program for prostate and colorectal CPS both during and after treatment. The OncoActive intervention was aimed at increasing PA of prostate and colorectal CPS. By increasing PA behavior, the intervention may have a positive influence on cancer recovery and prevent other health problems. OncoActive was based on a proven-effective and evidence-based intervention for adults over fifty, the Active Plus intervention [43, 44]. Systematic adaptation of this intervention to the new target group was guided by the IM protocol [48].

In the first step we identified that only a minority of prostate and colorectal CPS adhered to PA guidelines, even though PA has the potential to positively influence health problems and address the decreased quality of life resulting from their disease and their treatment. In step two we identified the importance to address the cancerspecific determinants of PA as they differ from the determinants in a general population of adults over fifty. In step three we added theoretical methods and practical applications to address the cancer-specific determinants. Methods like a pedometer for goal setting and monitoring were added based on the findings from the literature and our interviews. In step four the actual program was developed and pre- and pilot tests revealed a high 
appreciation from the target group. The implementation and evaluation plan were described in steps five and six.

IM proved to be a useful approach for translating an existing intervention to a new target group. The use of this systematic approach in the intervention development increases the likelihood of OncoActive still being effective in increasing PA behavior and meeting the needs and preference of the new target group [48]. Major strengths of using IM include the possibility to retain the core elements of the original, proven effective $[43,44]$ intervention and the use of behavioral change theories and scientific literature. The involvement of prostate and colorectal CPS, at three time points (i.e. interviews, pretest and pilot test), and health care professionals was also regarded as a strength in the development of the OncoActive intervention. As a result, the intervention content is assumed to fit the needs and preferences of the target group. This was preliminarily confirmed by the findings of the small scale pilot study in which the intervention as a whole and its elements received positive evaluations from the target group. In particular, the newly added pedometer was identified as useful. Pre-posttest analyses even revealed an increase in PA behavior.

One of the major challenges in adapting an existing intervention to a new target group was to constrain the amount of information provided to the participants. By adding cancer-specific content to the already existing content, texts inevitably become longer. A lot of written information might particularly be a problem for lower educated participants [148]. To avoid an overload of information, we decided to give preference to cancerspecific information as mentioned in step four. Additionally, intervention texts were edited and shortened by a professional editor. Furthermore, participants were able to revisit the website as many times as they wanted during the intervention period and as they received a printed version of their advice, they could easily stop and return or re-read the information.

Strengths of the OncoActive intervention itself include the fact that CPS can participate from their own home and at their own preferred time, as was indicated as a preference of CPS in previous research [21, 34, 38]. Therefore, the intervention is regarded as easily accessible for the target group. Additionally, as both an online version and printed materials are provided, CPS can choose which delivery channel they prefer, which is suggested to increase the reach of the OncoActive intervention [46]. As the OncoActive intervention is based on the concept of computer-tailoring, the information regarding PA could be made more personally relevant. Information perceived as personally relevant is assumed to be read more often and processed more thoughtfully, increasing the likelihood of behavior change or maintenance [120, 149]. With time and place not being an issue, and the use of an automated process like computer tailoring, the OncoActive intervention has the potential to reach a large group of CPS with minimal resources in terms of personnel, and can thus be offered at low costs once it has been developed.

Notwithstanding the potential strengths, a RCT should still provide further insight into the effectiveness of the OncoActive intervention. This RCT will also provide insight into the question of whether a systematically adapted version of an effective intervention is still effective for a different target group. If the OncoActive intervention indeed proves to be effective in increasing PA, an implementation study for future nationwide implementation would be the next logical step. Information on optimal conditions (hindering and facilitating factors) for implementation will be derived from interviews with representatives of organizations relevant for implementation. Furthermore, if proven effective, the content of the OncoActive intervention can be extended to the cancer-specific determinants of other cancer types.

\section{Abbreviations}

CPS: Cancer patients and survivors; CRC: Colorectal cancer; FAQ: Frequently asked questions; HRQoL: Health-related quality of life; IM: Intervention mapping; OA: Older adults; PA: Physical activity; PCa: Prostate cancer; PO: Performance objective; RCT: Randomized controlled trial; SCT: Social cognitive theory; TPB: Theory of planned behavior; TTM: Transtheoretical model

\section{Acknowledgments}

The authors would like to thank the cancer patients and survivors who participated in the development of the intervention in the interviews, pre-test and pilot test. We also want to thank the institutions who helped with the recruitment of these participants: Zuyderland Hospital (Heerlen), MAASTRO clinic (Maastricht), Dutch prostate cancer patient organization (prostaatkankerstichting.nl), Dutch colorectal cancer patient organization (Darmkanker

Nederland). Furthermore, we thank the healthcare professionals for their input on the intervention development and their critical review of intervention content.

We also would like to thank the hospitals who helped with the recruitment of participants for the randomized controlled trial: Admiraal de Ruyter Hospital (Goes/Vlissingen), Amphia Hospital (Breda), Albert Schweitzer Hospital (Dordrecht), Bernhoven (Uden), Catharina Hospital (Eindhoven), Canisius Wilhelmina Hospital (Nijmegen), Ikazia Hospital (Rotterdam), LangeLand Hospital (Zoetermeer), Maasstad Hospital (Rotterdam), MAASTRO clinic (Maastricht), Maastricht UMC+ (Maastricht), Rijnstate (Arnhem), St. Jans Gasthuis (Weert), Slingeland Hospital (Doetinchem), St. Anna Hospital (Geldrop), VieCuri Medical Centre (Venlo/Nenray), Zuyderland Hospital (Sittard/Heerlen).

\section{Funding}

This research was funded by the Dutch Cancer Society (KWF Kankerbestrijding, grant number NOU2012-5585).

\section{Availability of data and materials}

The datasets analyzed during the current study are available from the corresponding author upon reasonable request.

\section{Authors' contributions}

$\mathrm{LL}$ and $C B$ designed and wrote the original proposal. DP and RG were also involved in the original proposal. RG and EV were responsible for conducting the interviews, writing and programming of the intervention content and conducting the pre- and pilot test. $\mathrm{LL}$ and $\mathrm{CB}$ critically reviewed and approved the intervention content. RG, EV, HV, CB and LL were involved in construction of the questionnaires. EV and RG were responsible for the recruitment procedure. RG was responsible for drafting the manuscript. RG, 
$\mathrm{CB}, \mathrm{EV}, \mathrm{DP}, \mathrm{HV}$ and $\mathrm{LL}$ contributed to the writing of the manuscript and critically revised the manuscript for important intellectual content. All authors read and approved the final manuscript.

\section{Authors' information}

$\mathrm{RG}$ is a PhD candidate in health psychology, CB is an associate professor in health psychology, EV is a research assistant, DP is an assistant professor in health psychology, HV is a professor in health communication and $\mathrm{LL}$ is a professor in health psychology.

\section{Competing interests}

Hein de Vries is the scientific director of Vision2Health, a company that licenses evidence-based innovative computer-tailored health communication tools. The aim of Vision2Health is to implement evidence-based innovative health communication tools without financial gains. No other authors reported any conflicts of interest.

\section{Consent for publication}

Not applicable.

\section{Ethics approval and consent to participate}

The RCT was reviewed and approved by the Medical Ethics Committee of the Zuyderland hospital (NL47678.096.14). Participants provided written informed consent to participate in the trial. The study is registered in the Dutch Trial Register (NTR4296) on November 23rd 2013 and can be accessed at http://www.trialregister.n//trialreg/admin/rctview.asp?TC=4296.

\section{Publisher's Note}

Springer Nature remains neutral with regard to jurisdictional claims in published maps and institutional affiliations.

\section{Author details}

'Department of Psychology and Educational Sciences, Open University of the Netherlands, Heerlen, POBox 2960, 6401 DL HeerlenThe Netherlands. 2Department of Health Promotion, Maastricht University, Maastricht, The Netherlands.

Received: 23 August 2016 Accepted: 1 June 2017

Published online: 26 June 2017

\section{References}

1. Meulepas JM, Kiemeney LALM. Kanker in Nederland tot 2020. Trends en prognoses. [cancer in the Netherlands up to 2020: trends and prognoses]. In. Amsterdam: KWF Kankerbestrijding; 2011

2. Siesling SS, Sonke GS, de Raaf DHA, Jansen-Landheer MLEA: Kankerzorg in beeld [Cancer care in the picture]. In. Utrecht: Comprehensive Cancer Center of the Netherlands (IKNL); 2014.

3. Skolarus TA, Wolf AM, Erb NL, Brooks DD, Rivers BM, Underwood W 3rd Salner AL, Zelefsky MJ, Aragon-Ching JB, Slovin SF, et al. American Cancer Society prostate cancer survivorship care guidelines. CA Cancer J Clin. 2014; 64(4):225-49.

4. Harrington $\mathrm{CB}$, Hansen JA, Moskowitz M, Todd BL, Feuerstein M. It's not over when it's over: long-term symptoms in cancer survivors-a systematic review. Int J Psychiatry Med. 2010;40(2):163-81.

5. Wu HS, Harden JK. Symptom burden and quality of life in survivorship: a review of the literature. Cancer Nurs. 2015;38(1):E29-54

6. Denlinger CS, Barsevick AM. The challenges of colorectal cancer survivorship. Journal of the National Comprehensive Cancer Network: JNCCN. 2009; 7(8):883-93. quiz 894

7. Denlinger CS, Engstrom PF: Colorectal cancer survivorship: movement matters. Cancer prevention research (Philadelphia, Pa) 2011, 4(4):502-511.

8. Resnick MJ, Koyama T, Fan KH, Albertsen PC, Goodman M, Hamilton AS, Hoffman RM, Potosky AL, Stanford JL, Stroup AM, et al. Long-term functional outcomes after treatment for localized prostate cancer. N Engl J Med. 2013;368(5):436-45

9. Carlsson S, Drevin L, Loeb S, Widmark A, Lissbrant IF, Robinson D, Johansson E, Stattin P, Fransson P. Population-based study of long-term functional outcomes after prostate cancer treatment. BJU Int. 2016:117(6B):E36-45.

10. Bourke L, Boorjian SA, Briganti A, Klotz L, Mucci L, Resnick MJ, Rosario DJ, Skolarus TA, Penson DF. Survivorship and improving quality of life in men with prostate cancer. Eur Urol. 2015;68(3):374-83.
11. El-Shami K, Oeffinger KC, Erb NL, Willis A, Bretsch JK, Pratt-Chapman ML, Cannady RS, Wong SL, Rose J, Barbour AL, et al. American Cancer Society colorectal cancer survivorship care guidelines. CA Cancer J Clin. 2015;65(6): $428-55$.

12. Schmitz KH, Courneya KS, Matthews C, Demark-Wahnefried W, Galvão DA, Pinto BM, Irwin ML, Wolin KY, Segal RJ, Lucia A, et al. American College of Sports Medicine roundtable on exercise guidelines for cancer survivors. Med Sci Sports Exerc. 2010;42(7):1409-26.

13. Mishra SI, Scherer RW, Geigle PM, Berlanstein DR, Topaloglu O. Gotay CC. Snyder C: Exercise interventions on health-related quality of life for cancer survivors Cochrane Database Syst Rev. 2012;15(8):CD007566.

14. Mishra SI, Scherer RW, Snyder C, Geigle PM, Berlanstein DR, Topaloglu O. Exercise interventions on health-related quality of life for people with cancer during active treatment. Cochrane Database Syst Rev. 2012;15(8):CD008465.

15. Speck RM, Courneya KS, Mâsse LC, Duval S, Schmitz KH. An update of controlled physical activity trials in cancer survivors: a systematic review and meta-analysis. J Cancer Surviv. 2010:4(2):87-100.

16. Santa Mina D, Guglietti CL, Alibhai SM, Matthew AG, Kalnin R, Ahmad N, Lindner $U$, Trachtenberg J. The effect of meeting physical activity guidelines for cancer survivors on quality of life following radical prostatectomy for prostate cancer. J Cancer Surviv. 2014:8(2):190-8.

17. Thorsen L, Courneya KS, Stevinson C, Fossa SD. A systematic review of physical activity in prostate cancer survivors: outcomes, prevalence, and determinants. Support Care Cancer. 2008;16(9):987-97.

18. Fong DY, Ho JW, Hui BP, Lee AM, Macfarlane DJ, Leung SS, Cerin E, Chan WY, Leung IP, Lam SH et al: Physical activity for cancer survivors: meta-analysis of randomised controlled trials. BMJ (Clinical research ed) 2012, 344:e70.

19. Davies NJ, Batehup L, Thomas R. The role of diet and physical activity in breast, colorectal, and prostate cancer survivorship: a review of the literature. Br J Cancer. 2011;105(Suppl 1):S52-73.

20. Bourke L, Smith D, Steed L, Hooper R, Carter A, Catto J, Albertsen PC, Tombal B, Payne HA, Rosario DJ. Exercise for men with prostate cancer: a systematic review and meta-analysis. Eur Urol. 2016;69(4):693-703.

21. Szymlek-Gay EA, Richards R, Egan R. Physical activity among cancer survivors: a literature review. N Z Med J. 2011;124(1337):77-89.

22. van Waart $H$, Stuiver MM, van Harten WH, Geleijn E, Kieffer JM, Buffart LM, de Maaker-Berkhof M, Boven E, Schrama J, Geenen MM, et al. Effect of lowintensity physical activity and moderate- to high-intensity physical exercise during adjuvant chemotherapy on physical fitness, fatigue, and chemotherapy completion rates: results of the PACES randomized clinical trial. J Clin Oncol. 2015;33(17):1918-27.

23. Kampshoff CS, Chinapaw MJ, Brug J, Twisk JW, Schep G, Nijziel MR, van Mechelen W, Buffart LM. Randomized controlled trial of the effects of high intensity and low-to-moderate intensity exercise on physical fitness and fatigue in cancer survivors: results of the resistance and endurance exercise after ChemoTherapy (REACT) study. BMC Med. 2015;13:275.

24. Kenfield SA, Stampfer MJ, Giovannucci EL, Chan JM. Physical activity and survival after prostate cancer diagnosis in the health professionals follow-up study. J Clin Oncol. 2011;29(6):726-32.

25. Meyerhardt JA, Giovannucci EL, Holmes MD, Chan AT, Chan JA, Colditz GA, Fuchs CS. Physical activity and survival after colorectal cancer diagnosis. J Clin Oncol. 2006;24(22):3527-34.

26. Meyerhardt JA, Heseltine D, Niedzwiecki D, Hollis D, Saltz LB, Mayer RJ, Thomas J, Nelson H, Whittom R, Hantel A, et al. Impact of physical activity on cancer recurrence and survival in patients with stage III colon cancer: findings from CALGB 89803. J Clin Oncol. 2006;24(22):3535-41.

27. Rock CL, Doyle C, Demark-Wahnefried W, Meyerhardt J, Courneya KS, Schwartz AL, Bandera EV, Hamilton KK, Grant B, McCullough M, et al. Nutrition and physical activity guidelines for cancer survivors. CA Cancer J Clin. 2012;62(4):243-74.

28. Van Blarigan EL, Meyerhardt JA. Role of physical activity and diet after colorectal cancer diagnosis. J Clin Oncol. 2015;33(16):1825-34.

29. Blanchard CM, Courneya KS, Stein K. Cancer survivors' adherence to lifestyle behavior recommendations and associations with health-related quality of life: results from the American Cancer Society's SCS-II. J Clin Oncol. 2008;26(13):2198-204.

30. LeMasters TJ, Madhavan SS, Sambamoorthi U, Kurian S. Health behaviors among breast, prostate, and colorectal cancer survivors: a US populationbased case-control study, with comparisons by cancer type and gender. J Cancer Surviv. 2014;8(3):336-48. 
31. Chung JY, Lee DH, Park JH, Lee MK, Kang DW, Min J, Kim DI, Jeong DH, Kim NK, Meyerhardt JA, et al. Patterns of physical activity participation across the cancer trajectory in colorectal cancer survivors. Support Care Cancer. 2013; 21(6):1605-12

32. Basen-Engquist K, Carmack C, Blalock J, Baum G, Rahming W, DemarkWahnefried W. Predictors of cancer survivors' receptivity to lifestyle behavior change interventions. Cancer Epidemiol Biomark Prev. 2012;21:559.

33. Jones LW, Courneya KS. Exercise counseling and programming preferences of cancer survivors. Cancer Pract. 2002;10(4):208-15.

34. Murnane A, Geary B, Milne D. The exercise programming preferences and activity levels of cancer patients undergoing radiotherapy treatment. Support Care Cancer. 2012;20(5):957-62.

35. Blaney JM, Lowe-Strong A, Rankin-Watt J, Campbell A, Gracey JH. Cancer survivors' exercise barriers, facilitators and preferences in the context of fatigue, quality of life and physical activity participation: a questionnairesurvey. Psychooncology. 2013;22(1):186-94.

36. Buffart LM, Galvão DA, Brug J, Chinapaw MJM, Newton RU. Evidence-based physical activity guidelines for cancer survivors: current guidelines, knowledge gaps and future research directions. Cancer Treat Rev. 2014;40(2):327-40.

37. Demark-Wahnefried W. Current health behaviors and readiness to pursue life-style changes among men and women diagnosed with early stage prostate and breast carcinomas. Cancer. 2000;88(3):674-84.

38. McGowan EL, Speed-Andrews AE, Blanchard CM, Rhodes RE, Friedenreich CM, Culos-Reed SN, Courneya KS. Physical activity preferences among a populationbased sample of colorectal cancer survivors. Oncol Nurs Forum. 2013;40(1):44-52.

39. Velthuis MJ, May AM, Koppejan-Rensenbrink RA, Gijsen BC, van Breda E, de Wit GA, Schroder CD, Monninkhof EM, Lindeman E, van der Wall E, et al. Physical activity during cancer treatment (PACT) study: design of a randomised clinical trial. BMC Cancer. 2010;10:272.

40. Persoon S, Kersten MJ, Chinapaw MJ, Buffart LM, Burghout H, Schep G, Brug J, Nollet F: Design of the EXercise Intervention after Stem cell Transplantation (EXIST) study: a randomized controlled trial to evaluate the effectiveness and cost-effectiveness of an individualized high intensity physical exercise program on fitness and fatigue in patients with multiple myeloma or (non-) Hodgkin's lymphoma treated with high dose chemotherapy and autologous stem cell transplantation. BMC Cancer 2010, 10:671.

41. van Waart H, Stuiver MM, van Harten WH, Sonke GS, Aaronson NK. Design of the Physical exercise during adjuvant chemotherapy effectiveness study (PACES): a randomized controlled trial to evaluate effectiveness and costeffectiveness of physical exercise in improving physical fitness and reducing fatigue. BMC Cancer. 2010;10:673.

42. Kampshoff CS, Buffart LM, Schep G, van Mechelen W, Brug J, Chinapaw MJ. Design of the Resistance and Endurance exercise after ChemoTherapy (REACT) study: a randomized controlled trial to evaluate the effectiveness and cost-effectiveness of exercise interventions after chemotherapy on physical fitness and fatigue. BMC Cancer. 2010;10:658.

43. Peels DA, Bolman C, Golsteijn RHJ, de Vries H, Mudde AN, van Stralen MM, Lechner L. Long-term efficacy of a tailored physical activity intervention among older adults. Int J Behav Nutr Phys Act. 2013;10:104

44. van Stralen MM, de Vries H, Mudde AN, Bolman C, Lechner L. The long-term efficacy of two computer-tailored physical activity interventions for older adults: main effects and mediators. Health Psychol. 2011;30:442-52.

45. Peels DA, van Stralen MM, Bolman C, Golsteijn RH, de Vries H, Mudde AN, Lechner L. Development of web-based computer-tailored advice to promote physical activity among people older than 50 years. J Med Internet Res. 2012;14(2):e39.

46. Peels DA, Bolman C, Golsteijn RH, De Vries H, Mudde AN, van Stralen MM, Lechner L. Differences in reach and attrition between web-based and printdelivered tailored interventions among adults over 50 years of age: clustered randomized trial. J Med Internet Res. 2012;14(6):e179.

47. Miller KD, Siegel RL, Lin CC, Mariotto AB, Kramer JL, Rowland JH, Stein KD, Alteri R, Jemal A. Cancer treatment and survivorship statistics, 2016. CA Cancer J Clin. 2016;66(4):271-89.

48. Bartholomew Eldredge LK, Markham CM, Ruiter RAC, Fernandez ME, Kok G Parcel GS. Planning health promotion programs; an intervention mapping approach. 4th ed. San Francisco, CA: Jossey-Bass; 2016.

49. Dutch Cancer Registy [Nederlandse Kankerregistratie] [http://www. cijfersoverkanker.nl].

50. Jorgensen ML, Young JM, Solomon MJ. Optimal delivery of colorectal cancer follow-up care: improving patient outcomes. Patient related outcome measures. 2015;6:127-38.
51. Lynch BM, Boyle T, Winkler E, Occleston J, Courneya KS, Vallance JK. Patterns and correlates of accelerometer-assessed physical activity and sedentary time among colon cancer survivors. Cancer causes \& control: CCC. 2016;27(1):59-68.

52. Pinto BM, Papandonatos GD, Goldstein MG, Marcus BH, Farrell N. Homebased physical activity intervention for colorectal cancer survivors. Psychooncology. 2013;22(1):54-64.

53. Ottenbacher A, Sloane R, Snyder DC, Kraus W, Sprod L, Demark-Wahnefried W. Cancer-specific concerns and physical activity among recently diagnosed breast and prostate cancer survivors. Integrative cancer therapies. 2013;12(3):206-12.

54. Lynch BM, Cerin E, Owen N, Hawkes AL, Aitken JF. Prospective relationships of physical activity with quality of life among colorectal cancer survivors. J Clin Oncol. 2008;26(27):4480-7.

55. Schneider EC, Malin JL, Kahn KL, Ko CY, Adams J, Epstein AM. Surviving colorectal cancer: patient-reported symptoms 4 years after diagnosis. Cancer. 2007;110(9):2075-82.

56. Keogh JW, MacLeod RD. Body composition, physical fitness, functional performance, quality of life, and fatigue benefits of exercise for prostate cancer patients: a systematic review. J Pain Symptom Manag. 2012;43(1):96-110.

57. Baumann FT, Zopf EM, Bloch W. Clinical exercise interventions in prostate cancer patients-a systematic review of randomized controlled trials. Support Care Cancer. 2012;20(2):221-33.

58. Grimmett C, Bridgewater J, Steptoe A, Wardle J. Lifestyle and quality of life in colorectal cancer survivors. Qual Life Res Int J Qual Life Asp Treat Care Rehab. 2011;20(8):1237-45.

59. Galvao DA, Newton RU, Gardiner RA, Girgis A, Lepore SJ, Stiller A. Occhipinti S. Compliance to exercise-oncology guidelines in prostate cancer survivors and associations with psychological distress, unmet supportive care needs, and quality of life. Psychooncology: Chambers SK; 2015.

60. Knols R, Aaronson NK, Uebelhart D, Fransen J, Aufdemkampe G. Physical exercise in cancer patients during and after medical treatment: a systematic review of randomized and controlled clinical trials. J Clin Oncol. 2005;23(16):3830-42.

61. Thraen-Borowski KM, Trentham-Dietz A, Edwards DF, Koltyn KF, Colbert LH. Dose-response relationships between physical activity, social participation, and health-related quality of life in colorectal cancer survivors. J Cancer Surviv. 2013;7(3):369-78.

62. Buffart LM, Galvao DA, Brug J, Chinapaw MJ, Newton RU. Evidence-based physical activity guidelines for cancer survivors: current guidelines, knowledge gaps and future research directions. Cancer Treat Rev. 2014; 40(2):327-40.

63. Stuiver MM, Wittink HM, Velthuis MJ, Kool N, Jongert WAM: Physical Activity Intervention Oncology [Beweeginterventie Oncologie]. In: KNGF Standard [KNGF Standaard]. Amersfoort: Royal Dutch Society for Physiotherapy [Koninklijk Nederlands Genootschap voor Fysiotherapie (KNGF)]; 2011.

64. Coups EJ, Ostroff JS. A population-based estimate of the prevalence of behavioral risk factors among adult cancer survivors and noncancer controls. Prev Med. 2005;40(6):702-11.

65. Chipperfield K, Fletcher J, Millar J, Brooker J, Smith R, Frydenberg M, Oh T, Burney S. Factors associated with adherence to physical activity guidelines in patients with prostate cancer. Psychooncology. 2013;22(11):2478-86.

66. Stephenson LE, Bebb DG, Reimer RA, Culos-Reed SN. Physical activity and diet behaviour in colorectal cancer patients receiving chemotherapy: associations with quality of life. BMC Gastroenterol. 2009;9:60.

67. Hawkes AL, Lynch BM, Youlden DR, Owen N, Aitken JF. Health behaviors of Australian colorectal cancer survivors, compared with noncancer population controls. Support Care Cancer. 2008;16(10):1097-104.

68. Courneya KS, Karvinen KH, Vallance JKH: Exercise Motivation and Behavior Change. In: Handbook of Cancer Survivorship. edn. Edited by Feuerstein M. New York: Springer US; 2007: 113-132.

69. Jansen F, van Uden-Kraan CF, van Zwieten V, Witte BI, Verdonck-de Leeuw IM. Cancer survivors' perceived need for supportive care and their attitude towards self-management and eHealth. Support Care Cancer. 2015;23(6):1679-88.

70. Willems RA, Bolman CA, Mesters I, Kanera IM, Beaulen AA, Lechner L. Cancer survivors in the first year after treatment: the prevalence and correlates of unmet needs in different domains. Psychooncology. 2016;25(1):51-7.

71. Playdon M, Ferrucci LM, McCorkle R, Stein KD, Cannady R, Sanft T, Cartmel $B$. Health information needs and preferences in relation to survivorship care plans of long-term cancer survivors in the American Cancer Society's study of cancer survivors-I. J Cancer Surviv. 2016;10(4):674-85.

72. Pope C, Ziebland S, Mays N: Qualitative research in health care. Analysing qualitative data. BMJ (Clinical research ed) 2000, 320(7227):114-116. 
73. van Stralen MM, Kok G, de Vries H, Mudde AN, Bolman C, Lechner L. The active plus protocol: systematic development of two theory- and evidencebased tailored physical activity interventions for the over-fifties. BMC Public Health. 2008:8:399.

74. Irwin ML. Physical activity interventions for cancer survivors. Br J Sports Med. 2009:43(1):32-8

75. Wright M. Physical activity participation and preferences: developmental and oncology-related transitions in adolescents treated for cancer. Physiotherapy Canada Physiotherapie Canada. 2015;67(3):292-9.

76. Basen-Engquist K, Perkins H, Hughes DC: Health Behavior Change Counseling. In: ACSM's Guide to exercise and cancer survivorship. edn. Edited by Irwin ML. Champaing, IL: Human Kinetics; 2012: 141-152.

77. Pinto BM, Ciccolo JT. Physical activity motivation and cancer survivorship. Recent results in cancer research Fortschritte der Krebsforschung Progres dans les recherches sur le cancer. 2011;186:367-87.

78. Courneya KS, Friedenreich CM. Determinants of exercise during colorectal cancer treatment: an application of the theory of planned behavior. Oncol Nurs Forum. 1997;24(10):1715-23.

79. Blanchard CM, Courneya KS, Rodgers WM, Murnaghan DM. Determinants of exercise intention and behavior in survivors of breast and prostate cancer: an application of the theory of planned behavior. Cancer Nurs. 2002;25(2):88-95

80. Courneya K, Friedenreich C, Arthur K, Bobick T. Understanding exercise motivation in colorectal cancer patients: a prospective study using the theory of planned behavior. Rehabilitation psychology. 1999;44(1):68-84.

81. Andrykowski MA, Beacham AO, Schmidt JE, Harper FW. Application of the theory of planned behavior to understand intentions to engage in physical and psychosocial health behaviors after cancer diagnosis. Psychooncology. 2006;15(9):759-71.

82. Keogh JW, Shepherd D, Krageloh CU, Ryan C, Masters J, Shepherd G, MacLeod R. Predictors of physical activity and quality of life in New Zealand prostate cancer survivors undergoing androgen-deprivation therapy. N Z Med J. 2010;123(1325):20-9.

83. Hunt-Shanks TT, Blanchard CM, Baker F, Hann D, Roberts CS, McDonald J, Livingston M, Witt C, Ruiterman J, Ampela R, et al. Exercise use as complementary therapy among breast and prostate cancer survivors receiving active treatment: examination of exercise intention. Integrative cancer therapies. 2006;5(2):109-16.

84. Speed-Andrews AE, Rhodes RE, Blanchard CM, Culos-Reed SN, Friedenreich CM, Belanger LJ, Courneya KS. Medical, demographic and social cognitive correlates of physical activity in a population-based sample of colorectal cancer survivors. European journal of cancer care. 2012;21(2):187-96.

85. Ungar N, Sieverding M, Ulrich CM, Wiskemann J. What explains the intention to be physically active in cancer patients? Different determinants for active and insufficiently active patients. J Psychosoc Oncol. 2015;33(1):15-33.

86. Mosher CE, Lipkus I, Sloane R, Snyder DC, Lobach DF, Demark-Wahnefried W. Long-term outcomes of the FRESH START trial: exploring the role of selfefficacy in cancer survivors' maintenance of dietary practices and physical activity. Psychooncology. 2013;22(4):876-85

87. Pinto BM, Rabin C, Dunsiger S. Home-based exercise among cancer survivors: adherence and its predictors. Psychooncology. 2009;18(4):369-76.

88. Pinto BM, Floyd A. Theories underlying health promotion interventions among cancer survivors. Semin Oncol Nurs. 2008;24(3):153-63.

89. De Vries H, Mesters I, van de Steeg H, Honing C. The general public's information needs and perceptions regarding hereditary cancer: an application of the integrated change model. Patient Educ Couns. 2005;56(2):154-65.

90. De Vries H, Mesters I, Riet JV, Willems K, Reubsaet A. Motives of Belgian adolescents for using sunscreen: the role of action plans. Cancer Epidemiol Biomark Prev. 2006;15(7):1360-6.

91. de Vries H, Mudde A, Leijs I, Charlton A, Vartiainen E, Buijs G, Clemente MP, Storm H, Gonzalez Navarro A, Nebot M, et al. The European smoking prevention framework approach (EFSA): an example of integral prevention. Health Educ Res. 2003;18(5):611-26.

92. Ajzen I: From Intentions to Actions: A Theory of Planned Behavior. In: Action Control: From Cognition to Behavior. edn. Edited by Kuhl J, Beckmann J. Berlin, Heidelberg: Springer Berlin Heidelberg; 1985: 11-39.

93. Bandura A. Social foundations of thought and action: a social cognitive theory. NJ: Prentice Hall: Englewood Cliffs; 1986.

94. Prochaska JO, DiClemente CC. Stages and processes of self-change of smoking: toward an integrative model of change. J Consult Clin Psychol. 1983;51(3):390-5.
95. Janz NK, Becker MH: The health belief model: a decade later. Health Educ Q 1984, 11(1):1-47.

96. Locke EA, Latham GP: A theory of goal setting \& task performance: prentice hall; 1990.

97. Gollwitzer PM, Schaal B. Metacognition in action: the importance of implementation intentions. Personality and social psychology review: an official journal of the Society for Personality and Social Psychology, Inc. 1998;2(2):124-36.

98. Schwarzer R: The Health Action Approach (HAPA). In., edn.; 2009.

99. Schwarzer R. Modeling health behavior change: how to predict and modify the adoption and maintenance of health behaviors. Appl Psychol. 2008:57(1):1-29.

100. Baumeister RF, Vohs KD. Handbook of self-regulation: research, theory, and applications. New York: The Guilford Press; 2004

101. Boekaerts M, Pintrich PR, Zeidner M. Handbook of self-regulation. New York: Academic Press; 2001.

102. Zimmerman BJ. Attaining self-regulation: a social cognitive perspective. In: Handbook of self-regulation. Edn. Edited by Boekaerts M, Pintrich PR, Zeidner M. San Diego: Academic Press; 2000.

103. Weinstein ND. The precaution adoption process. Health Psychol. 1988;7(4):355-86.

104. Lee MK, Park HA, Yun YH, Chang YJ. Development and formative evaluation of a web-based self-management exercise and diet intervention program with tailored motivation and action planning for cancer survivors. JMIR research protocols. 2013;2(1):e11.

105. Galvao DA, Taaffe DR, Spry N, Newton RU. Physical activity and genitourinary cancer survivorship. Recent results in cancer research Fortschritte der Krebsforschung Progres dans les recherches sur le cancer. 2011;186:217-36.

106. Holtzman J, Schmitz K, Babes G, Kane RL, Duval S, Wilt TJ, MacDonald RM, Rutks I. Effectiveness of behavioral interventions to modify physical activity behaviors in general populations and cancer patients and survivors. Evidence report/technology assessment (Summary). 2004;102:1-8.

107. Schmitz KH, Holtzman J, Courneya KS, Masse LC, Duval S, Kane R. Controlled physical activity trials in cancer survivors: a systematic review and metaanalysis. Cancer Epidemiol Biomark Prev. 2005;14(7):1588-95.

108. Sellar CM, Courneya KS. Physical activity and gastrointestinal cancer survivorship. Recent results in cancer research Fortschritte der Krebsforschung Progres dans les recherches sur le cancer. 2011;186:237-53.

109. Stevinson C, Campbell KL, Sellar CM, Courneya KS: Physical Activity for Cancer Survivors. In: Handbook of Cancer Survivorship. edn. Edited by Feuerstein M. Boston, MA: Springer US; 2007: 249-268.

110. Golsteijn RHJ, Bolman C, Volders E, Peels DA, De Vries H, Lechner L: Development of an e-Health physical activity intervention for prostate and colorectal cancer survivors: the OncoActive+ intervention. Psycho-Oncology 2014, 23(Supplement S3):258.

111. Charlier C, Van Hoof E, Pauwels E, Lechner L, Spittaels H, Bourgois J, De Bourdeaudhuij I. Treatment-related and psychosocial variables in explaining physical activity in women three weeks to six months post-treatment of breast cancer. Patient Educ Couns. 2012;89(1):171-7.

112. Charlier C, Van Hoof E, Pauwels E, Lechner L, Spittaels H, De Bourdeaudhuij I. The contribution of general and cancer-related variables in explaining physical activity in a breast cancer population 3 weeks to 6 months posttreatment. Psychooncology. 2013;22(1):203-11.

113. Comprehensive Cancer Center of the Netherlands (IKNL): Cancer rehabilitation. Nation-wide guideline, Version: 1.0. In: Empowerment. Utrecht: Comprehensive Cancer Center of the Netherlands (IKNL); 2011.

114. Krebs P, Prochaska JO, Rossi JS. A meta-analysis of computer-tailored interventions for health behaviour change. Prev Med. 2010;51:214-21.

115. Kreuter MW, Skinner CS. Tailoring: what's in a name? Health Educ Res. 2000;15(1):1-4.

116. Short CE, James EL, Plotnikoff RC, Girgis A. Efficacy of tailored-print interventions to promote physical activity: a systematic review of randomised trials. Int J Behav Nutr Phys Act. 2011;8:113.

117. Broekhuizen K, Kroeze W, Van Poppel MNM, Oenema A, Brug J. A systematic review of randomized controlled trials on the effectiveness of computertailored physical activity and dietary behavior promotion programs: an update. Annals of behavioral medicine: a publication of the Society of Behavioral Medicine. 2012;44(2):259-86.

118. Kroeze W, Werkman A, Brug J. A systematic review of randomized trial on the effectiveness of computer-tailored education on physical activity and dietary behaviors. Annals of behavioral medicine: a publication of the Society of Behavioral Medicine. 2006;31(3):205-23. 
119. Neville LM, O'Hara B, Milat A. Computer-tailored physical activity behavior change interventions targeting adults: a systematic review. Int J Behav Nutr Phys Act. 2009;6:30.

120. Noar SM, Benac CN, Harris MS. Does tailoring matter? Meta-analytic review of tailored print health behavior change interventions. Psychol Bull. 2007;133(4):673-93.

121. Kuijpers W, Groen WG, Aaronson NK, van Harten WH. A systematic review of web-based interventions for patient empowerment and physical activity in chronic diseases: relevance for cancer survivors. J Med Internet Res. 2013;15(2):e37.

122. Kanera IM, Bolman CA, Willems RA, Mesters I, Lechner L. Lifestyle-related effects of the web-based Kanker Nazorg Wijzer (cancer aftercare guide) intervention for cancer survivors: a randomized controlled trial. J Cancer Surviv. 2016;

123. Ungar N, Wiskemann J, Sieverding M. Physical activity enjoyment and selfefficacy as predictors of cancer Patients' physical activity level. Front Psychol. 2016;7:898.

124. Koring M, Parschau L, Lange D, Fleig L, Knoll N, Schwarzer R. Preparing for physical activity: pedometer acquisition as a self-regulatory strategy. Applied psychology Health and well-being. 2013;5(1):136-47.

125. Bravata DM, Smith-Spangler C, Sundaram V, Gienger AL, Lin N, Lewis R, Stave CD, Olkin I, Sirard JR. Using pedometers to increase physical activity and improve health: a systematic review. JAMA. 2007;298(19):2296-304.

126. Kang M, Marshall SJ, Barreira TV, Lee JO. Effect of pedometer-based physical activity interventions: a meta-analysis. Res Q Exerc Sport. 2009;80(3):648-55.

127. Knols RH, de Bruin ED, Shirato K, Uebelhart D, Aaronson NK. Physical activity interventions to improve daily walking activity in cancer survivors. BMC Cancer. 2010;10:406

128. De Cocker K, Charlier C, Van Hoof E, Pauwels E, Lechner L, Bourgois J, Spittaels H, Vandelanotte C, De Bourdeaudhuij I. Development and usability of a computer-tailored pedometer-based physical activity advice for breast cancer survivors. European journal of cancer care. 2015;24(5):673-82.

129. Craike MJ, Livingston PM, Botti M. An exploratory study of the factors that influence physical activity for prostate cancer survivors. Support Care Cancer. 2011;19(7):1019-28.

130 Blaney J, Lowe-Strong A, Rankin J, Campbell A, Allen J, Gracey J. The cancer rehabilitation journey: barriers to and facilitators of exercise among patients with cancer-related fatigue. Phys Ther. 2010;90(8):1135-47.

131. Speed-Andrews AE, McGowan EL, Rhodes RE, Blanchard CM, Culos-Reed SN, Friedenreich CM, Courneya KS. Identification and evaluation of the salient physical activity beliefs of colorectal cancer survivors. Cancer Nurs. 2014;37(1):14-22.

132. Loh SY, Chew SL, Lee SY. Physical activity and women with breast cancer: insights from expert patients. Asian Pacific journal of cancer prevention: APJCP. 2011;12(1):87-94.

133. Courneya KS, Jones LW, Mackey JR, Fairey AS. Exercise beliefs of breast cancer survivors before and after participation in a randomized controlled trial. International journal of behavioral medicine. 2006;13(3):259-64.

134. Rogers LQ, Courneya KS, Verhulst S, Markwell S, Lanzotti V, Shah P. Exercise barrier and task self-efficacy in breast cancer patients during treatment. Support Care Cancer. 2006;14(1):84-90.

135. Rogers LQ, Courneya KS, Shah P, Dunnington G, Hopkins-Price P. Exercise stage of change, barriers, expectations, values and preferences among breast cancer patients during treatment: a pilot study. European journal of cancer care. 2007:16(1):55-66

136. Lynch BM, Owen N, Hawkes AL, Aitken JF. Perceived barriers to physical activity for colorectal cancer survivors. Support Care Cancer. 2010;18(6):729-34.

137. Ekman A, Dickman PW, Klint A. Weiderpass E. Litton J: Feasibility of Using Web-based Questionnaires in Large Population-based Epidemiological Studies Eur J Epidemiol. 2006;21(2):103-11.

138. Kongsved SM, Basnov M, Holm-Christensen $\mathrm{K}$, Hjollund NH. Response rate and completeness of questionnaires: a randomized study of internet versus paper-and-pencil versions. J Med Internet Res. 2007;9(3):e25.

139. Peels DA, de Vries H, Bolman C, Golsteijn RH, van Stralen MM, Mudde AN, Lechner L. Differences in the use and appreciation of a web-based or printed computer-tailored physical activity intervention for people aged over 50 years. Health Educ Res. 2013;28(4):715-31.

140. Golsteijn RHJ, Bolman C, Peels DA, Volders E, De Vries H, Lechner L: OncoActive: a pre-experimental pilot to assess the feasibility, usability and appreciation of a systematically adapted, evidence-based physical activity intervention for prostate and colorectal cancer patients. In: Abstract book of the Annual Conference of the International Society of Behavioral Nutrition and Physical Activity: 3-6 June 2015; Edinburgh; 2015: 297.
141. Brooke J: SUS: a 'quick and dirty' usability scale. In: Usability Evaluation In Industry. edn. Edited by Jordan PW, Thomas B, McClelland IL, Weerdmeester B. London: Taylor \& Francis; 1996: 189-194.

142. Wendel-Vos GCW, Schuit AJ, Saris WH, Kromhout D. Reproducibility and relative validity of the short questionnaire to assess health-enhancing physical activity. J Clin Epidemiol. 2003:56:1163-9.

143. Vercoulen JH, Swanink CM, Fennis JF, Galama JM, van der Meer JW, Bleijenberg G. Dimensional assessment of chronic fatigue syndrome. J Psychosom Res. 1994;38(5):383-92.

144. Zigmond AS, Snaith RP. The hospital anxiety and depression scale. Acta Psychiatr Scand. 1983:67(6):361-70.

145. Bjelland I, Dahl AA, Haug TT, Neckelmann D. The validity of the hospital anxiety and depression scale. An updated literature review. J Psychosom Res. 2002;52(2):69-77.

146. Watson M, Homewood J. Mental adjustment to cancer scale: psychometric properties in a large cancer cohort. Psychooncology. 2008;17(11):1146-51.

147. Aaronson NK, Ahmedzai S, Bergman B, Bullinger M, Cull A, Duez NJ, Filiberti A, Flechtner H, Fleishman SB, de Haes JC, et al. The European Organization for Research and Treatment of cancer QLQ-C30: a quality-of-life instrument for use in international clinical trials in oncology. J Natl Cancer Inst. 1993; 85(5):365-76.

148. Verkissen MN, Ezendam NP, Fransen MP, Essink-Bot ML, Aarts MJ, Nicolaije KA, Vos MC, Husson O. The role of health literacy in perceived information provision and satisfaction among women with ovarian tumors: a study from the population-based PROFILES registry. Patient Educ Couns. 2014;95(3): $421-8$.

149. de Vries H, Brug J. Computer-tailored interventions motivating people to adopt health promoting behaviours: introduction to a new approach. Patient Educ Couns. 1999;36(2):99-105.

150. Falzon C, Chalabaev A, Schuft L, Brizzi C, Ganga M, d'Arripe-Longueville F: Beliefs about physical activity in sedentary cancer patients: an in-depth interview study in France. Asian Pacific journal of cancer prevention: APJCP 2012, 13(12):6033-6038

151. Peeters C, Stewart A, Segal R, Wouterloot E, Scott CG, Aubry T. Evaluation of a cancer exercise program: patient and physician beliefs. Psychooncology. 2009;18(8):898-902.

152. Mustian KM, Griggs JJ, Morrow GR, McTiernan A, Roscoe JA, Bole CW, Atkins $J N$, Issell BF. Exercise and side effects among 749 patients during and after treatment for cancer: a University of Rochester Cancer Center Community Clinical Oncology Program Study. Support Care Cancer. 2006;14(7):732-41.

153. Fisher A, Wardle J, Beeken RJ, Croker H, Williams K, Grimmett C. Perceived barriers and benefits to physical activity in colorectal cancer patients. Support Care Cancer. 2016;24(2):903-10.

154. Courneya KS, Friedenreich CM, Quinney HA, Fields AL, Jones LW, Vallance JK, Fairey AS. A longitudinal study of exercise barriers in colorectal cancer survivors participating in a randomized controlled trial. Annals of behavioral medicine: a publication of the Society of Behavioral Medicine. 2005;29(2):147-53.

155. Ottenbacher AJ, Day RS, Taylor WC, Sharma SV, Sloane R, Snyder DC, Kraus WE, Demark-Wahnefried W. Exercise among breast and prostate cancer survivors-what are their barriers? J Cancer Surviv. 2011:5(4):413-9.

156. Anderson AS, Caswell S, Wells M, Steele RJ. Macaskill S: "it makes you feel so full of life" live well, a feasibility study of a personalised lifestyle programme for colorectal cancer survivors. Support Care Cancer. 2010;18(4):409-15.

\section{Submit your next manuscript to BioMed Central and we will help you at every step:}

- We accept pre-submission inquiries

- Our selector tool helps you to find the most relevant journal

- We provide round the clock customer support

- Convenient online submission

- Thorough peer review

- Inclusion in PubMed and all major indexing services

- Maximum visibility for your research

Submit your manuscript at www.biomedcentral.com/submit 